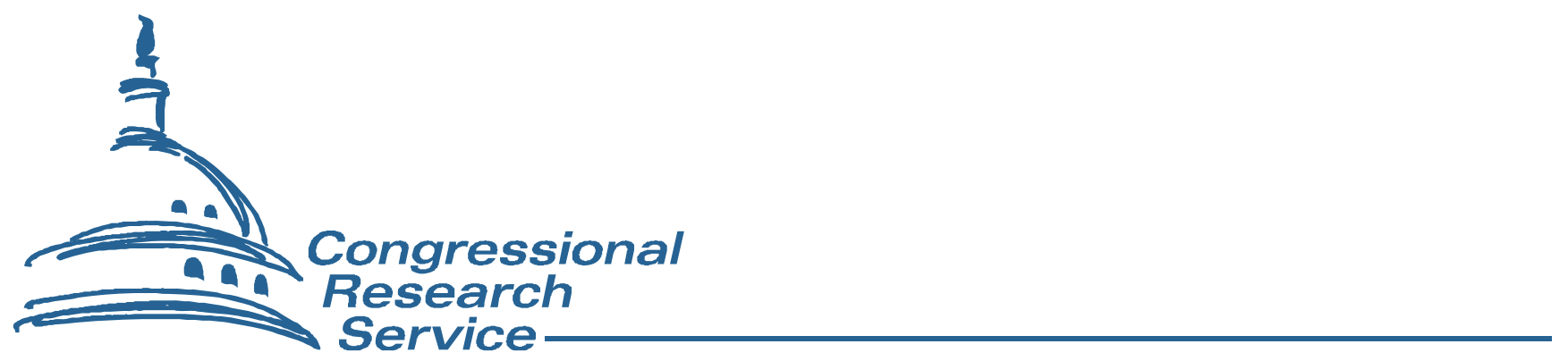

\title{
Medicare Part D Prescription Drug Benefit
}

\section{Patricia A. Davis}

Specialist in Health Care Financing

June 1, 2009 


\section{Summary}

The Medicare Prescription Drug, Improvement, and Modernization Act of 2003 (MMA, P.L. 108-173) established an outpatient voluntary prescription drug benefit under a new Medicare Part D, effective January 1, 2006. Drug coverage is provided through private prescription drug plans (PDPs), which offer only prescription drug coverage, or through Medicare Advantage (MA) prescription drug plans (MA-PDs), which offer prescription drug coverage that is integrated with the health care coverage they provide to Medicare beneficiaries under Part $\mathrm{C}$. These private plans bear some of the financial risk for drug costs; however, federal subsidies covering the bulk of the risk are provided to encourage participation.

At a minimum, plans offer "standard coverage" or alternative coverage with actuarially equivalent benefits. They may also offer enhanced benefits. All plans are required to meet certain minimum requirements, including those related to beneficiary protections. However, there are significant differences among plans in terms of benefit design, drugs included on plan formularies (i.e., list of covered drugs), cost-sharing applicable for particular drugs, and monthly premiums. In general, beneficiaries can enroll in a plan, or change plan enrollment, when they first become eligible for Medicare or during the annual open enrollment period. In 2009, beneficiaries could choose from among close to 50 PDP options in each of the 34 PDP regions. As plan sponsors may change their plan offerings from year to year, beneficiaries need to carefully review their plan choices annually to make sure that the plans they select continue to meet their needs.

A major focus of the drug benefit is the enhanced coverage provided to low-income individuals who enroll in Part D. Persons with incomes below $150 \%$ of poverty and assets below certain limits may receive assistance with some portion of their premiums and cost-sharing charges. Individuals enrolled in both Medicare and Medicaid (dual-eligibles), as well as certain other lowincome enrollees, are enrolled in plans with premiums at or below the low-income subsidy level for the region. In recent years, the number of plans available to low-income subsidy recipients for no monthly premium has been declining.

In 2009, approximately 27 million beneficiaries are enrolled in either a PDP or a MA-PD, and over a third of them are receiving the low-income subsidy. In total, about $90 \%$ of Medicare beneficiaries have some form of drug coverage either through Medicare or other type of insurance. Total expenditures for Part D are projected to exceed \$60 billion in 2009.

While early start-up issues with the Part D program have generally been resolved, some issues remain and others are emerging. Discussions regarding the overall structure of program benefits, costs to Medicare and beneficiaries, the availability of plans for low-income enrollees, and oversight of the program are likely to continue. This report will be updated as events warrant. 


\section{Contents}

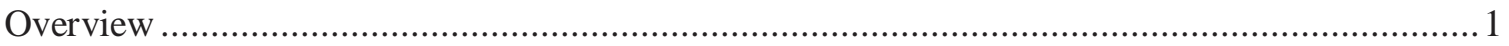

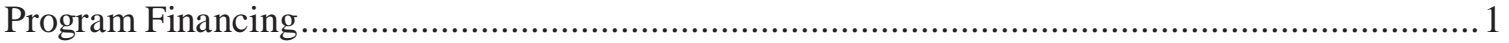

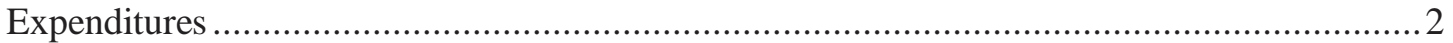

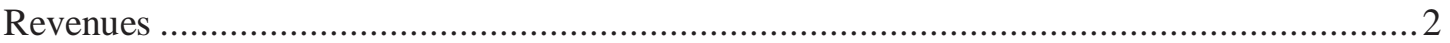

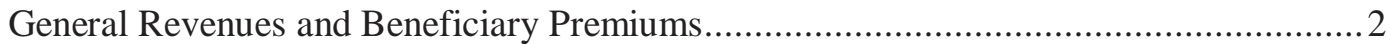

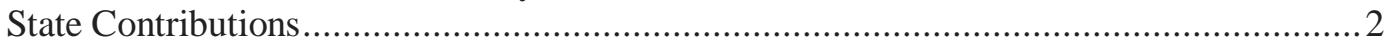

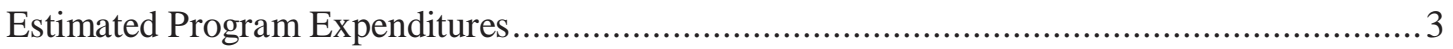

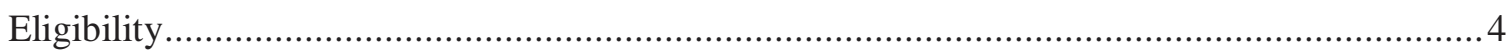

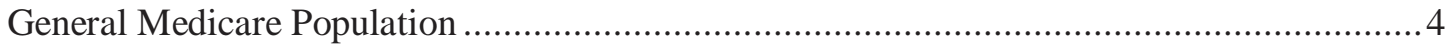

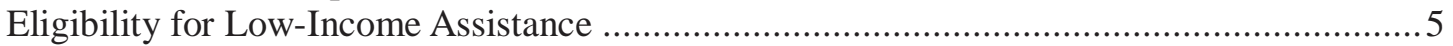

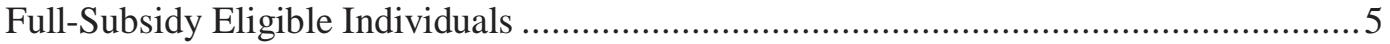

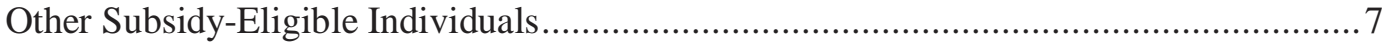

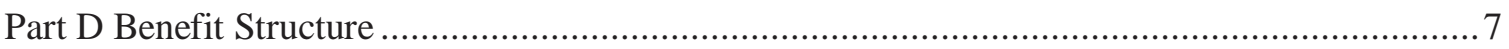

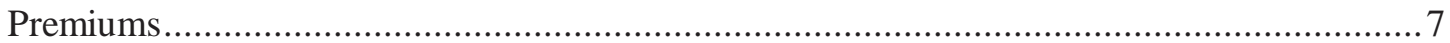

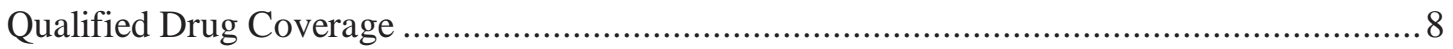

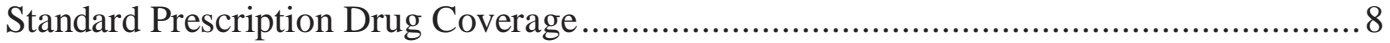

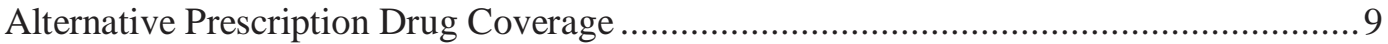

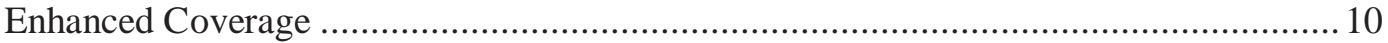

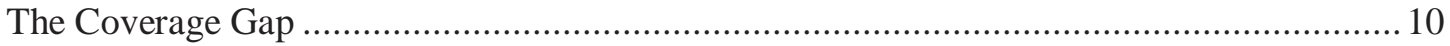

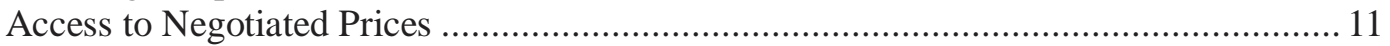

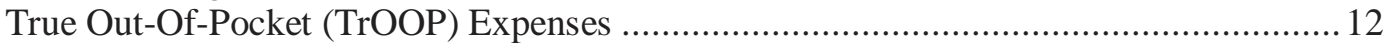

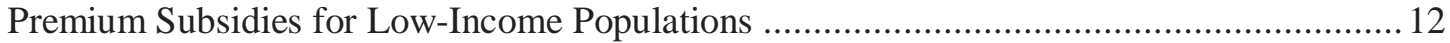

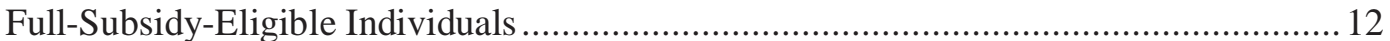

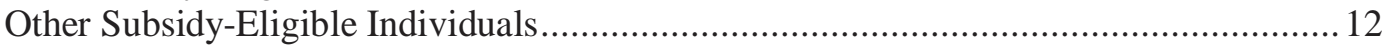

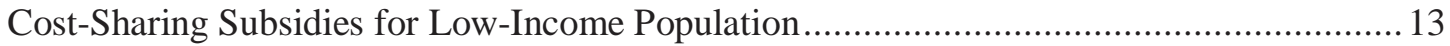

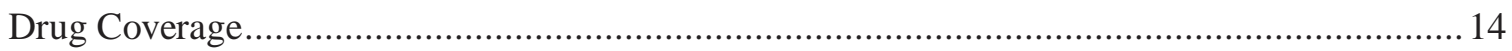

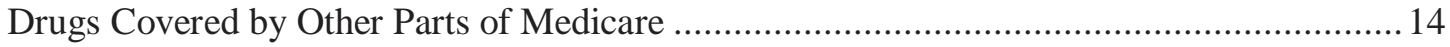

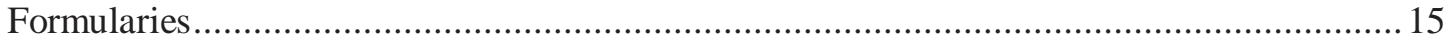

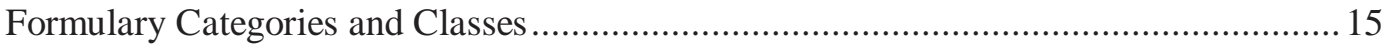

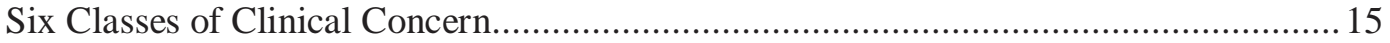

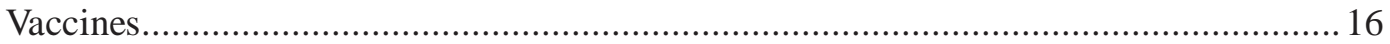

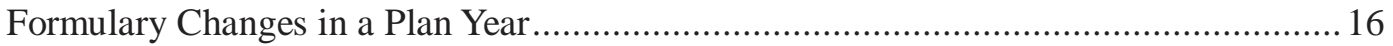

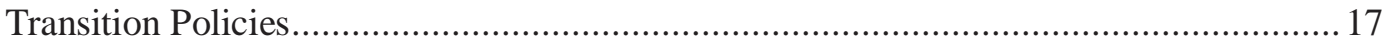

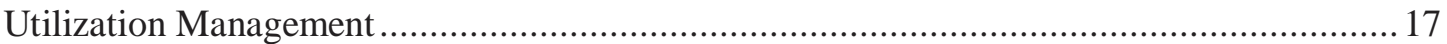

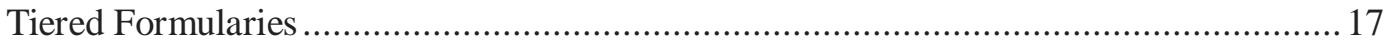

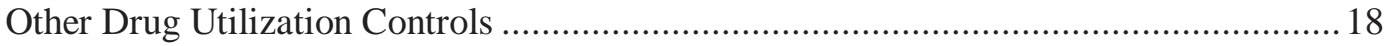

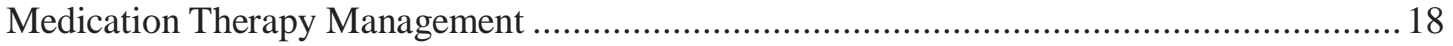

Coverage Determinations, Appeals, and Grievances ........................................................... 19

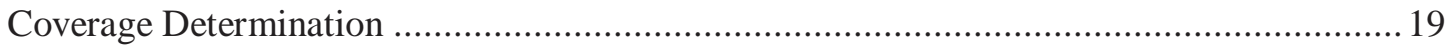

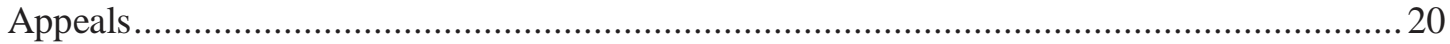

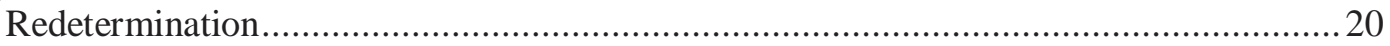

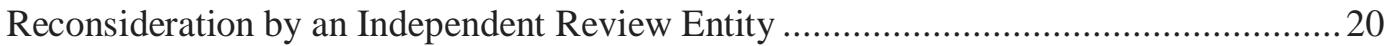

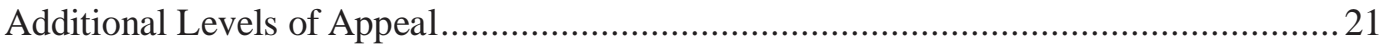

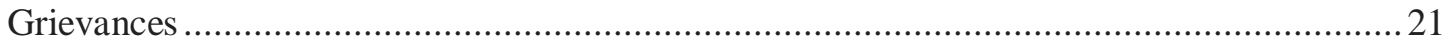

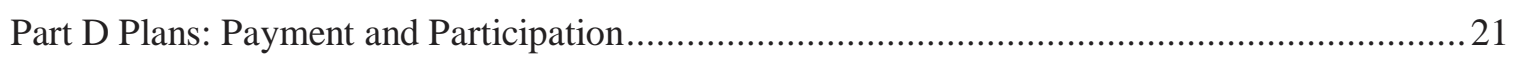




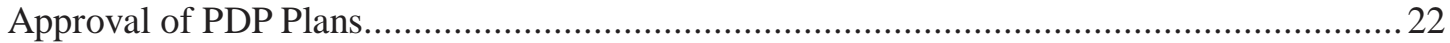

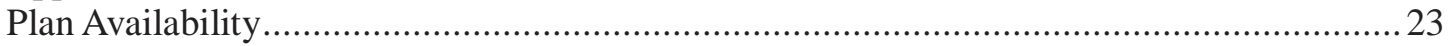

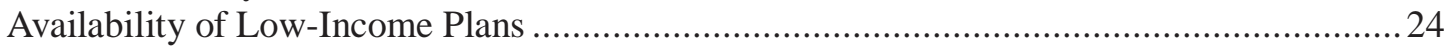

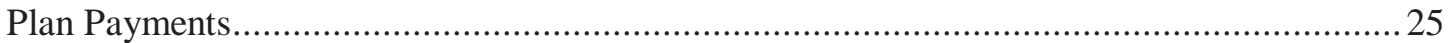

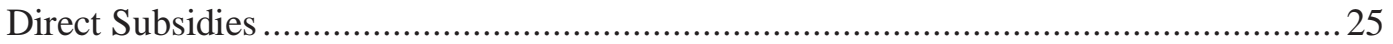

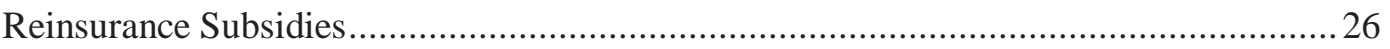

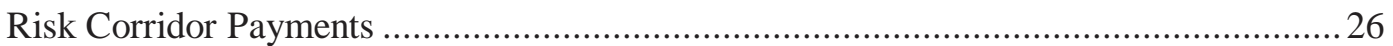

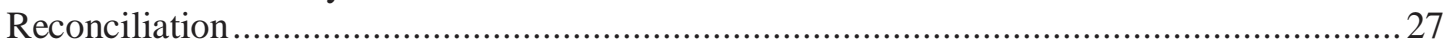

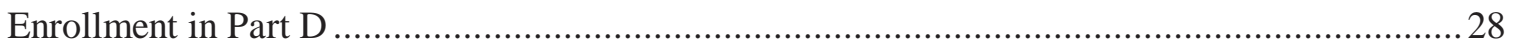

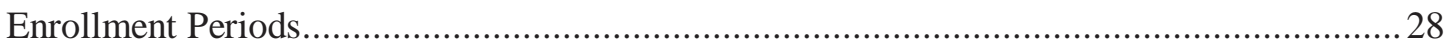

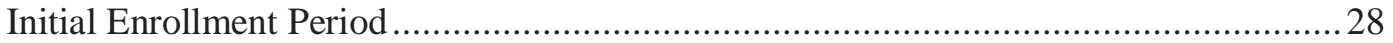

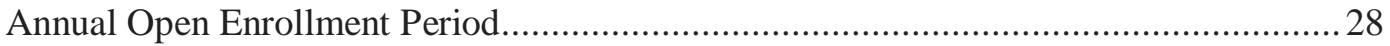

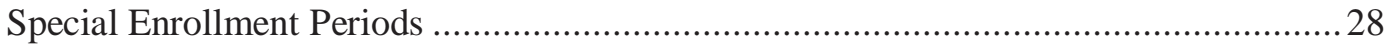

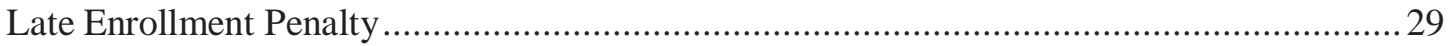

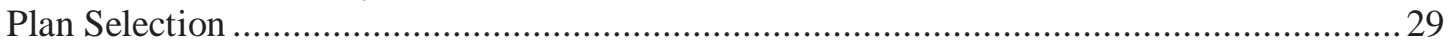

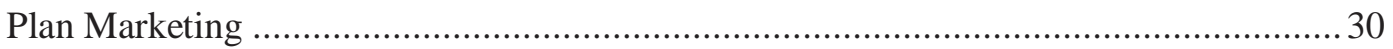

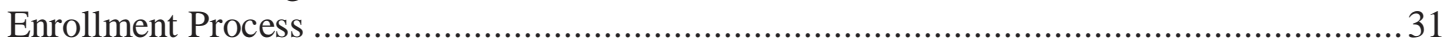

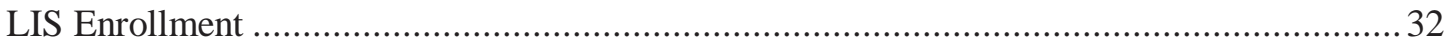

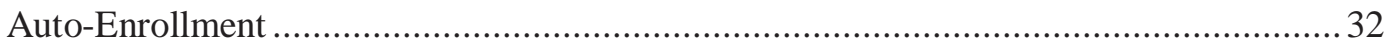

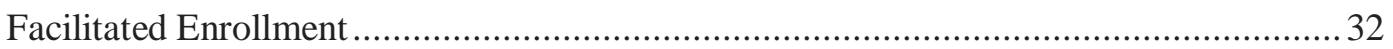

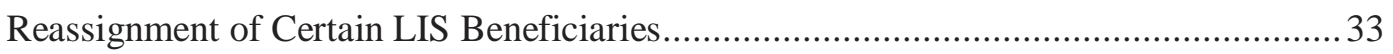

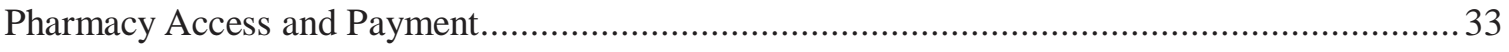

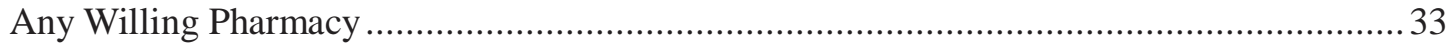

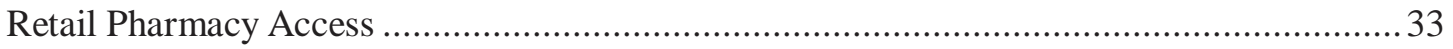

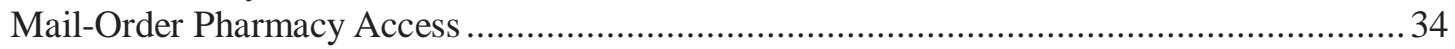

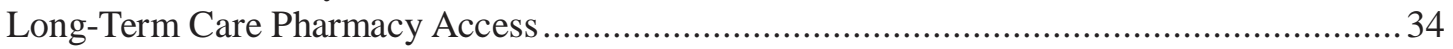

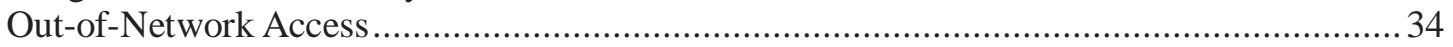

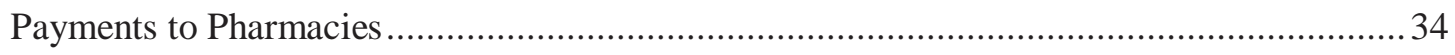

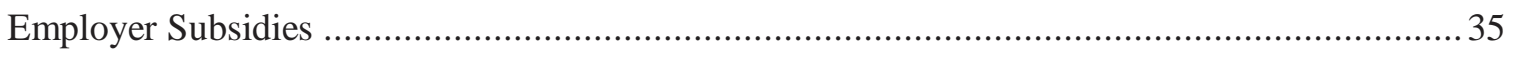

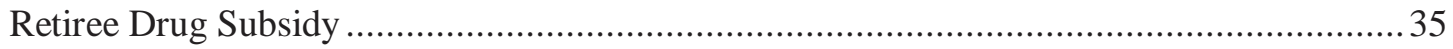

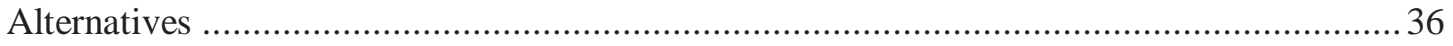

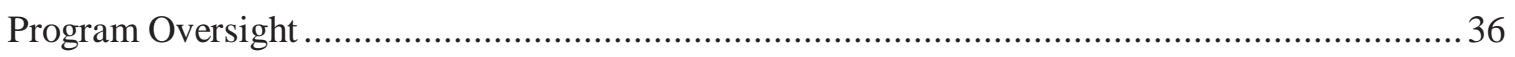

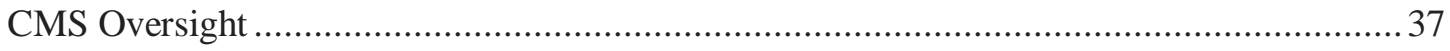

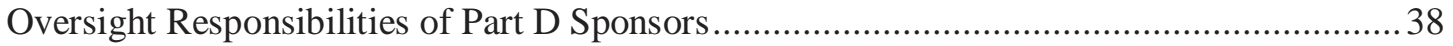

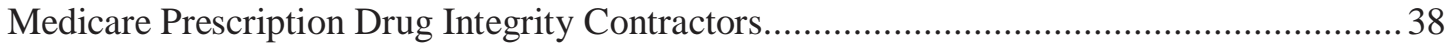

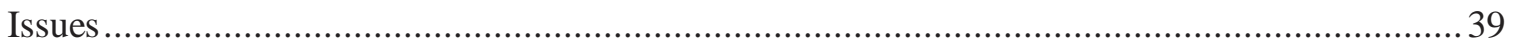

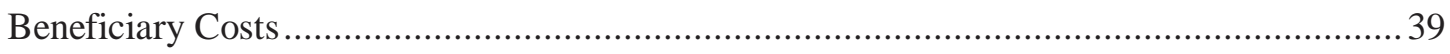

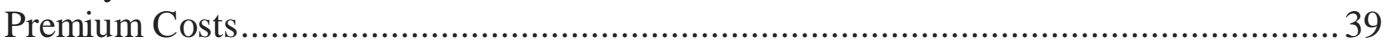

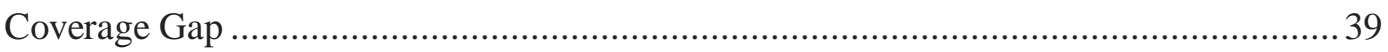

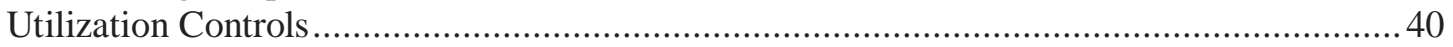

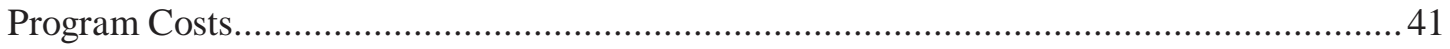

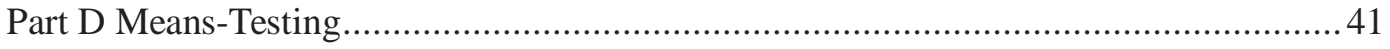

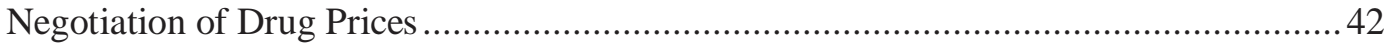

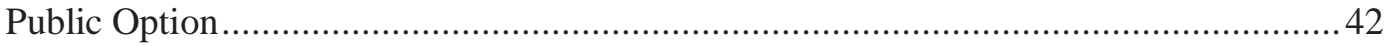

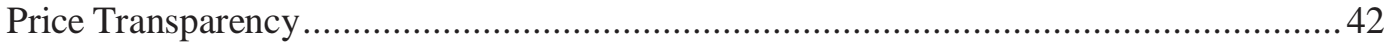

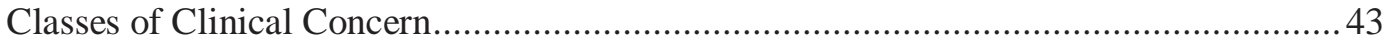

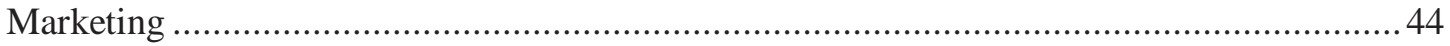

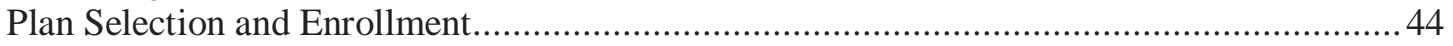




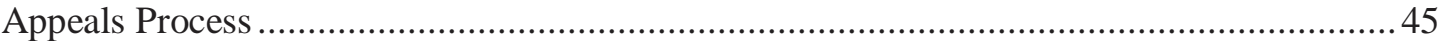

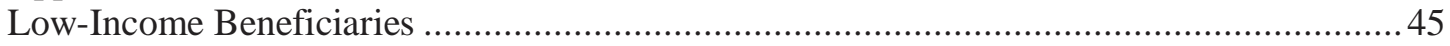

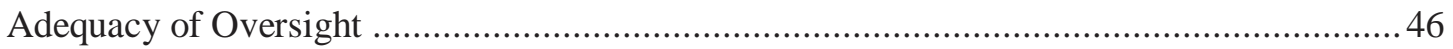

\section{Figures}

Figure 1. Standard Medicare Prescription Drug Benefit, 2009.................................................9

Figure 2. Prescription Drug Plans Available by Region, 2009 ..................................................23

Figure 3. Low-Income Subsidy Eligible Prescription Drug Plans, 2009 ...................................25

\section{Tables}

Table 1. Statement of Operations of Part D Account, CY2008 ….............................................

Table 2. Total Medicare Beneficiaries with Prescription Drug Coverage, 2009.......................... 4

Table 3. LIS-Eligible Medicare Beneficiaries with Drug Coverage, 2009..................................5

Table 4. Overview of How Medicare Beneficiaries Qualify for LIS ....................................... 6

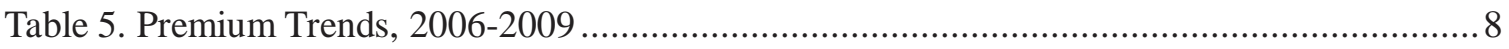

Table 6. Sliding Scale Premium for Partial-Subsidy-Eligible Individuals ................................. 12

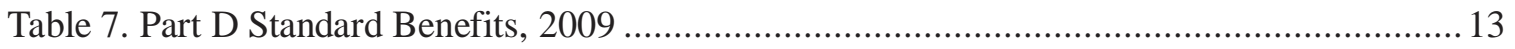

Table 8. Plan Liability Under Risk Corridor Provisions …....................................................... 27

\section{Contacts}

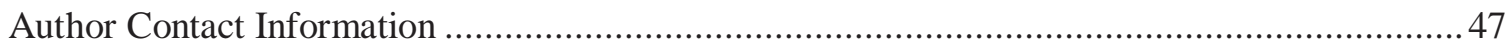

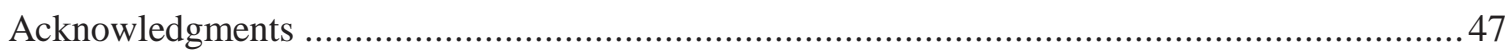




\section{Overview}

In January 2009, the Medicare prescription drug program began its fourth year of operation. The Medicare Prescription Drug, Improvement, and Modernization Act of 2003 (MMA, P.L. 108-173) created this voluntary outpatient prescription drug benefit under a new Medicare Part D, effective January 1, 2006. At that time, Medicare replaced Medicaid as the primary source of drug coverage for beneficiaries covered under both programs (called dual eligibles). Since the MMA's enactment, several statutes have modified or amended the Part D program. These statutes include the QI, TMA, and Abstinence Programs Extension and Hurricane Katrina Unemployment Relief Act of 2005 (P.L. 109-91); the Tax Relief and Health Care Act of 2006 (TRHCA, P.L. 109-432); and the Medicare Improvements for Patients and Providers Act of 2008 (MIPPA, P.L. 110-275).

Prescription drug coverage is provided through private prescription drug plans (PDPs), which offer only prescription drug coverage, or through Medicare Advantage (MA) prescription drug plans (MA-PDs), which offer prescription drug coverage that is integrated with the health care coverage they provide to Medicare beneficiaries under Part C. The MMA also provides for subsidy payments to sponsors of qualified retiree prescription drug plans (the retiree drug subsidy) to encourage retention of non-Part D employer-sponsored benefits. In 2009, approximately 27 million beneficiaries are enrolled in either a PDP or a MA-PD and another 6 million are enrolled in a subsidized retiree prescription drug plan. In total, about $90 \%$ of Medicare beneficiaries have some form of drug coverage.

A major focus of the drug benefit is the enhanced coverage provided to low-income individuals who enroll in Part D. Individuals with incomes below $150 \%$ of the federal poverty limit and limited assets are eligible for the low-income subsidy (LIS). The LIS reduces beneficiaries' outof-pocket spending by paying for all or some of the Part D monthly premium and annual deductible, and limits drug copayments to a nominal price. Persons with the lowest incomes receive the highest level of benefits. In 2009, approximately 9.6 million beneficiaries (about onethird of Part D enrollees) are receiving the low-income subsidy.

The Part D program relies on private plans to provide coverage and to bear some of the financial risk for drug costs; federal subsidies covering the bulk of the risk are provided to encourage participation. While all plans must meet certain minimum requirements, there are significant variations among them in benefit design, including differences in premiums, drugs included on plan formularies (i.e., list of covered drugs), and cost-sharing applicable for particular drugs. In 2009, there are a total of 1,689 PDPs and 2,039 MA-PDs nationwide.

\section{Program Financing}

The MMA established within the Supplementary Medical Insurance (SMI) trust fund the Medicare Prescription Drug Account to be used in conjunction with the Part D prescription drug program (see Table 1). The Part D program is primarily funded through general revenues. The appropriation language adopted for the Part D account allows substantial flexibility in the amount

\footnotetext{
${ }^{1}$ The regulations governing the Part D program are set forth in 42 CFR Part 423-Voluntary Medicare Prescription Drug Benefit.
} 
of general revenues available to the account. This flexibility eliminates the need for a contingency reserve; as a result, assets in the Part D account are generally low.

\section{Expenditures}

According to the 2009 Annual Trustees Report, during calendar year (CY) 2008, total Part D expenditures were approximately $\$ 49.3$ billion. ${ }^{2}$ This amount included the combined costs of prescription drugs provided by Part D plans to enrollees and Medicare payments to employersponsored retiree health plans ( $\$ 49.0$ billion). The remaining $\$ 0.3$ billion in expenditures covered federal administrative expenses, including expenses incurred by the Department of Health and Human Services (HHS), the Social Security Administration (SSA), and the Department of the Treasury in administering Part D. Such duties include making payments to Part D plans and implementing fraud and abuse control activities.

\section{Revenues}

The major sources of revenue for the Part D account include general revenues, beneficiary premiums, and state contributions. Total Part D revenues in CY2008 were $\$ 49.4$ billion.

\section{General Revenues and Beneficiary Premiums}

General revenues are transferred from the Treasury to the Part D Account on an as-needed basis to cover the portion of program expenditures funded by federal subsidies. In CY2008, contributions received from the general fund of the Treasury amounted to $\$ 37.3$ billion, which accounted for about $76 \%$ of total Part D revenue.

Beneficiaries may have their premiums deducted from their Social Security or other federal benefit payments; these are then forwarded to Part D plans on their behalf. Alternatively, they can pay their premiums directly to the Part D plans. In 2008, $\$ 1.9$ billion in premium amounts were withheld from Social Security benefit checks or other federal benefit payments. Another $\$ 3.1$ billion in premiums were paid directly to the plans by beneficiaries. Beneficiary premiums accounted for approximately $10 \%$ of revenues (see "Premiums" and "Part D Plans: Payment and Participation").

\section{State Contributions}

After Part D drug coverage and low-income subsidies became available in 2006, Medicaid is no longer the primary payer of drug costs for full-benefit dual-eligible beneficiaries. However, MMA contained a provision (labeled by some as the "clawback provision") that requires states to pay the Part D account in the SMI trust fund a portion of the costs that they would have incurred for this population if they were still the primary payer. Starting in 2006, states paid $90 \%$ of these estimated costs. This percentage phases down over a 10-year period to $75 \%$ in 2015 . In 2008 , these state payments amounted to $\$ 7.1$ billion, or about $14 \%$ of revenues.

\footnotetext{
2009 Annual Report of the Boards of Trustees of the Federal Hospital Insurance and Federal Supplementary Medical Insurance Trust Funds, May 12, 2009, Table III.C17, p. 115.
} 
Table I. Statement of Operations of Part D Account, CY 2008

(in millions)

\begin{tabular}{lr}
\hline Total Assets at Beginning of Year & $\$ 801.0$ \\
\hline \multicolumn{1}{c}{ Revenues } & $\$ 49,371.5$ \\
Premiums from Enrollees & $4,998.6$ \\
Premiums deducted from Social Security checks & $1,873.3$ \\
Premiums paid directly to plans & $3,125.3$ \\
Government Contributions & $37,255.4$ \\
Prescription drug benefits & $36,979.3$ \\
Administrative expenses & 276.1 \\
Payments from States & $7,104.8$ \\
Interest on Investments & 12.7 \\
Expenditures & $\$ 49,261.2$ \\
Benefit Payments & $48,982.1$ \\
Federal Administrative Expenses & 279.1 \\
Assets of Fund at End of Year & $\$ 911.4$ \\
\hline
\end{tabular}

Source: Table III.CI7, 2009 Annual Report of the Boards of Trustees of the Federal Hospital Insurance and Federal Supplementary Insurance Trust Funds.

Note: Totals may not add due to rounding.

\section{Estimated Program Expenditures}

The growth in prescription drug spending under Part D has been lower than projected at the beginning of the program. Actual prescription drug costs for 2006 and 2007 were significantly lower than the costs estimated in the bids submitted by plans for the 2006 plan year, and somewhat lower than the trustees' estimates in their 2007 report. This may have occurred, in part, because the actual rebates that drug plans received from manufacturers and the use of generic drugs were higher than expected.

Medicare expenditures for the Part D drug benefit were approximately $\$ 47$ billion in CY2006 and are expected to exceed $\$ 60$ billion in 2009. The 2009 Medicare Trustees Report projects that total Part D expenditures, based on intermediate estimates, will reach $\$ 140.8$ billion in 2018. The per capita benefits are projected to increase from $\$ 1,517$ in 2008 to $\$ 3,177$ in 2018 . These cost estimates have been adjusted downward from the 2008 report, primarily due to an expected decline in the number of new drug products expected to reach the market. Additionally, the trustees are projecting higher income from premiums due to an expected change in methodology used to calculate risk scores. ${ }^{3}$ Part D expenditures are still, however, projected to increase rapidly over the next ten years due to further expected increases in Part D enrollment and cost growth

\footnotetext{
${ }^{3}$ Medicare makes monthly prospective payments to Part D sponsors based on average plan bids that are adjusted for the expected case mix of enrollees in a particular plan. The new methodology would base the risk scores on the health status of individuals enrolled in Part D rather than on all those eligible for the benefit, starting in 2010. CMS published this policy in its April 6, 2009 release of the CY2010 "Medicare Advantage Capitation Rates and Medicare Advantage and Part D Payment Policies".
} 
rates that are expected to exceed those for other categories of medical spending. The Trustees Report cautions that there is a high level of uncertainty surrounding these cost projections, as there is still little experience with this new benefit upon which to base conclusions.

\section{Eligibility}

\section{General Medicare Population}

In general, anyone entitled to Medicare Part A and/or enrolled in Part B is eligible to enroll in a Medicare prescription drug plan. The individual must also permanently reside in the service area of a PDP. Anyone living abroad or who is incarcerated is not eligible, as he or she cannot meet this requirement. For most people, joining Part D is voluntary. (Dual-eligible beneficiaries are automatically signed up for Part D, as described in "LIS Enrollment.") Beneficiaries cannot be denied coverage for health reasons or for high utilization of prescription drugs.

As of February 2009, of the 45.2 Medicare beneficiaries eligible for Part D, approximately 26.7 million are enrolled in either a stand-alone prescription drug plan (17.5 million) or in a Medicare Advantage or other Medicare health plan with drug coverage (9.2 million). An additional 6.0 million have prescription drug coverage through a former employer that is receiving a federal subsidy for a portion of the coverage. About 8.2 million have drug coverage through another source, such as the Federal Employees Health Benefits program or TRICARE. Approximately 4.5 million beneficiaries (about 10\%) have no drug coverage (see Table 2).

Table 2.Total Medicare Beneficiaries with Prescription Drug Coverage, 2009 (in millions)

\begin{tabular}{lcc}
\hline \multicolumn{1}{c}{ Description } & $\mathbf{2 0 0 9}$ & Percent of Eligible \\
\hline Medicare Beneficiaries Eligible for Part D & $\mathbf{4 5 . 2}$ & $\mathbf{1 0 0 . 0 \%}$ \\
Medicare Part D & $\mathbf{2 6 . 7}$ & $\mathbf{5 8 . 9}$ \\
Stand-Alone PDP & 17.5 & 38.6 \\
MA with Drug Coverage & 9.0 & 19.8 \\
Other Plan Types & 0.2 & 0.4 \\
Medicare Retiree Drug Subsidy (RDS) & 6.0 & $\mathbf{1 3 . 2}$ \\
Other Drug Coverage & $\mathbf{8 . 2}$ & $\mathbf{1 8 . 0}$ \\
TRICARE & 1.0 & 2.1 \\
FEHB Retiree Coverage & 1.0 & 2.2 \\
Veterans Affairs Coverage & 1.6 & 3.5 \\
Active Workers with Medicare Secondary Payer & 1.8 & 4.0 \\
Multiple Sources of Creditable Coverage & 0.8 & 1.7 \\
Retiree Coverage (Not RDS) & 1.5 & 3.3 \\
Medigap and Other Individual Insurance & 0.2 & 0.4 \\
State Pharmaceutical Assistance Programs & $<0,1$ & $<0.1$ \\
Indian Health Service Coverage & $<0.1$ & $<0.1$ \\
Other Sources & 0.3 & 0.7 \\
Total Beneficiaries with Drug Coverage & $\mathbf{4 0 . 8}$ & $\mathbf{9 0 . 1}$ \\
\hline
\end{tabular}

Source: CMS, February 2009, http://www.cms.hhs.gov/PrescriptionDrugCovGenln/0I_Overview.asp.

Note: Totals may not add due to rounding. 


\section{Eligibility for Low-Income Assistance}

Some beneficiaries with limited income and resources may qualify for assistance with a portion of their Part D premiums, cost-sharing, and other out-of-pocket expenses. As of February 2009, an estimated 12.5 million Medicare beneficiaries are eligible for low-income subsidies (LIS). Of these, nearly 9.6 million are receiving subsidies because they automatically qualify as full dual eligibles, Medicare Savings Program (MSP) recipients, ${ }^{4}$ or Supplemental Security Income (SSI) recipients. ${ }^{5}$ Another 1.5 million beneficiaries receive low-income subsidies because they applied and were determined eligible. Finally, 2.3 million low-income Medicare beneficiaries are thought to be eligible for low-income subsidies but are not receiving them (see Table 3).

Table 3. LIS-Eligible Medicare Beneficiaries with Drug Coverage, 2009 (in millions)

\begin{tabular}{lc}
\hline Description & Total LIS-Eligible Beneficiaries \\
\hline $\begin{array}{l}\text { Total Beneficiaries Eligible for Low-Income } \\
\text { Subsidy }\end{array}$ & 12.5 \\
Less: Drug Coverage from Medicare & 9.6 \\
$\quad$ CMS-Deemed Full Dual Eligibles & 6.3 \\
CMS-Deemed MSP and SSI Recipients & 1.8 \\
LIS Approved and Not Deemed & 1.5 \\
Less: Drug Coverage from Former & $<0.1$ \\
Employer & \\
Less: Additional Sources of Creditable Drug & $\mathbf{0 . 4}$ \\
Coverage & 0.4 \\
$\quad$ Veterans Affairs (VA) Coverage & $<0.1$ \\
$\quad$ Indian Health Service Coverage & $<0.1$ \\
Less: Anticipated Facilitated Enrollments & 2.3 \\
Total Remaining LIS-Eligible Beneficiaries &
\end{tabular}

Source: CMS, February 2009, http://www.cms.hhs.gov/PrescriptionDrugCovGenln/0I_Overview.asp.

\section{Full-Subsidy Eligible Individuals}

Certain groups of Medicare beneficiaries automatically qualify (and are deemed eligible) for the full low-income subsidy. Dual eligibles who qualify for Medicaid based on their income and assets are automatically deemed eligible for Medicare prescription drug low-income subsidies. Additionally, those who receive premium and/or cost-sharing assistance from Medicaid through

\footnotetext{
${ }^{4}$ The Medicare Savings program includes the Qualified Medicare Beneficiary program (QMB), Specified Low-Income Medicare Beneficiary program (SLMB), and Qualified Individual program (QI). These programs help Medicare beneficiaries of modest means pay all or some of Medicare's cost-sharing amounts (i.e., premiums, deductibles, and copayments). To qualify, an individual must be eligible for Medicare and must meet certain income limits which change annually.

${ }^{5}$ Supplemental Security Income (SSI) is a federal income supplement program funded by general tax revenues (not Social Security taxes). It is designed to help aged, blind, and disabled people who have little or no income, and it provides cash to meet basic needs for food, clothing, and shelter.
} 
the Medicare savings programs, plus those eligible for SSI cash assistance, are automatically deemed eligible for low-income subsidies and need not apply for them. This group includes all eligible persons who (1) have incomes below $135 \%$ of the federal poverty level $(\$ 14,621$ for an individual and $\$ 19,670$ for a couple in 2009) ${ }^{6}$ and (2) have resources in 2009 below $\$ 8,100$ for an individual and $\$ 12,910$ for a couple (increased each year by the percentage increase in the consumer price index, or CPI). ${ }^{7}$ (See Table 4.)

CMS deems individuals automatically eligible for LIS effective as of the first day of the month that the individual attains the qualifying status (e.g., becomes eligible for Medicaid, MSP, or SSI). The end date is, at a minimum, through the end of the calendar year within which the individual becomes eligible. Beneficiaries who are deemed LIS-eligible for any month during the period of July through December of one year are deemed eligible through the end of the following calendar year. CMS changes an individual's deemed status mid-year only when such a change qualifies the beneficiary for a reduced co-payment obligation.

Eligibility for the LIS is not always continuous from year to year. For example, LIS beneficiaries who lose eligibility for Medicaid, MSP, or SSI during the year are not automatically qualified to receive the LIS the next year. CMS notifies these individuals in September of each year that their LIS-deemed status will end on December 31 of that year. Such individuals may reapply for the LIS, as they may qualify for the LIS through the application process (see "LIS Enrollment"). According to CMS, 447,000 beneficiaries lost their deemed status between 2008 and 2009.

Table 4. Overview of How Medicare Beneficiaries Qualify for LIS

\begin{tabular}{|c|c|c|c|c|}
\hline Eligibility & $\begin{array}{l}\text { People with Medicare and } \\
\text { Medicaid benefits }\end{array}$ & Basis & $\begin{array}{l}\text { Data } \\
\text { Source }\end{array}$ & $\begin{array}{c}\text { Changes During } \\
\text { the Year }\end{array}$ \\
\hline $\begin{array}{l}\text { Full Subsidy } \\
\text { Eligible }\end{array}$ & $\begin{array}{l}\text { - Full Medicaid benefits } \\
\text { - Partial Dual (QMB-only, } \\
\text { SLMB-only, QI) } \\
\text { SSI benefits }\end{array}$ & $\begin{array}{l}\text { Automatically } \\
\text { qualify }\end{array}$ & State Files & $\begin{array}{l}\text { Qualify for a full } \\
\text { calendar year } \\
\text { - Generally only } \\
\text { favorable } \\
\text { changes will } \\
\text { occur }\end{array}$ \\
\hline $\begin{array}{l}\text { Other } \\
\text { Subsidy } \\
\text { Eligible }\end{array}$ & $\begin{array}{l}\text { Limited Income and } \\
\text { Resources }\end{array}$ & Must apply & $\begin{array}{l}\text { SSA } \\
\text { (almost } \\
\text { all) or } \\
\text { states }\end{array}$ & $\begin{array}{l}\text { - Some events can } \\
\text { impact status } \\
\text { throughout the } \\
\text { year } \\
\text { Extra help can } \\
\text { increase, } \\
\text { decrease or } \\
\text { terminate }\end{array}$ \\
\hline
\end{tabular}

Source: CMS, August 7, 2008, memo from Anthony Culotta to Part D Plan Sponsors, on Re-Determination of Low-Income Subsidy Eligibility for 2009.

\footnotetext{
${ }^{6}$ Social Security benefits, Veterans benefits, public and private pensions, annuities, and in-kind support are counted as income.

${ }^{7}$ These resource limits include $\$ 1,500$ per person for burial expenses.
} 


\section{Other Subsidy-Eligible Individuals}

Other individuals with limited income and resources who do not automatically qualify may apply for the low-income subsidy and have their eligibility determined by either the Social Security Administration or their state Medicaid agency. This group includes all other persons who (1) are enrolled in a PDP plan or MA-PD plan, (2) have incomes below $150 \%$ of poverty $(\$ 16,245$ for an individual and $\$ 21,855$ for a couple in 2009), and (3) have assets in 2009 below $\$ 12,510$ for an individual and $\$ 25,010$ for a couple (increased in future years by the percentage increase in the CPI). According to SSA, ${ }^{8}$ in 2008, approximately $17 \%$ of low-income subsidy applicants who were determined ineligible would have qualified based on income alone, but had excess assets.

An individual who applies and is determined eligible for the LIS is eligible effective the first day of the month in which the individual submitted an application. In most cases, this means that LIS status is applied retroactively. For example, if a beneficiary is already enrolled in a Part D plan, the Part D sponsor must take steps to ensure that the beneficiary has been reimbursed for any premiums or cost-sharing the member had paid that should have been covered by the subsidy.

Individual LIS determinations are made for a period not to exceed 12 months. After that time, if the individual is found ineligible, the subsequent end date would be established by the agency that made the decision (either the state or SSA). The end date is always the last day of a calendar month but may occur in any month of the year.

\section{Part D Benefit Structure}

Medicare law sets out a standard prescription drug benefit structure. Plan sponsors may, however, offer different benefit designs and cost-sharing requirements, as long as they meet certain specifications. Under the standard benefit structure, with some exceptions, over the course of the year a beneficiary is responsible for paying (1) a monthly premium, (2) an annual deductible, and (3) co-payments or co-insurance for drug purchases. Additionally, for a certain period called the "coverage gap," beneficiaries may be responsible for the full cost of their drugs. The actual costs to beneficiaries under Part D will vary and depend upon the benefit structure and coverage offered by a particular plan, the costs and amount of drugs needed, and whether the beneficiary receives some form of assistance.

\section{Premiums}

The majority of beneficiaries enrolled in Part D pay monthly premiums for Part D coverage. On average, beneficiary premiums represent roughly $25.5 \%$ of the cost of basic coverage. However, the amount of the premiums can vary by the plan selected.

Beneficiary premiums are based on the average bid submitted by drug plans for basic benefits (the base beneficiary premium) for each year and are adjusted to reflect the difference between the plan's standardized bid amount and the nationwide average bid. (In 2009, the base beneficiary

\footnotetext{
${ }^{8}$ Social Security Administration's analysis of Medicare Database, February 1, 2008, cited in "Medicare Part D LowIncome Subsidy: SSA Continues to Approve Applicants, but Millions of Individuals Have Not Yet Applied," GAO-08812T, May 22, 2008.
} 
monthly premium is $\$ 30.36$. See Table 5.) Thus, beneficiaries in plans with higher costs for standard coverage face higher than average premiums for such coverage, while enrollees in lower cost plans pay lower than average premiums for such coverage. Additionally, enrollees in MA-PD plans may see lower premiums if their plans buy down the Part D premium. ${ }^{9}$ The monthly premium is the same for all persons enrolled in the plan (except for those receiving low-income subsidies or those subject to a late enrollment penalty).

Table 5. Premium Trends, 2006-2009

\begin{tabular}{lcccc}
\hline \multicolumn{1}{c}{ Premium } & $\mathbf{2 0 0 6}$ & $\mathbf{2 0 0 7}$ & $\mathbf{2 0 0 8}$ & $\mathbf{2 0 0 9}$ \\
\hline Base Premium & $\mathbf{2}$ & $\$ 27.35$ & $\$ 27.93$ & $\$ 30.36$ \\
$\begin{array}{l}\text { Average PDP } \\
\text { Premium }\end{array}$ & 26.03 & 27.39 & 29.86 & 37.27 \\
$\begin{array}{l}\text { Average MA-PDP } \\
\text { Premium }\end{array}$ & 12.08 & 10.35 & 11.97 & 15.15 \\
\hline
\end{tabular}

Source: CMS, "Release of the Part D National Average Monthly Bid Amount, the Medicare Part D Base Beneficiary Premium, the Part D Regional Low-Income Premium Subsidy Amounts, and the Medicare Advantage Regional Benchmarks," August 15, 2006, August 13, 2007, and August 14, 2008; Medicare Payment Advisory Commission, "Report to Congress, Medicare Payment Policy”, March 2009, March 2008, March 2007.

a. The base premium represents $25.5 \%$ of the national average monthly bid amount for basic coverage.

b. Average PDP and MA-PD premiums for 2006 and 2007 were weighted by actual enrollment in each plan. The average premiums for 2008 and 2009 were weighted by estimated enrollments.

\section{Qualified Drug Coverage}

Under Medicare Part D, PDPs and MA-PDs are required to offer a minimum set of benefits. This minimum set, referred to as "qualified coverage," may include either the standard prescription drug coverage established by Medicare or alternative prescription drug coverage with benefits that are at least of equivalent dollar value (actuarially equivalent). Plans also have the option of offering "enhanced coverage," which exceeds the value of the defined standard coverage.

\section{Standard Prescription Drug Coverage}

The Part D standard benefit includes a deductible paid by the beneficiary (\$295 in 2009); 75\% of costs paid by the program and $25 \%$ of costs paid by the beneficiary up to the initial coverage limit ( $\$ 2,700$ in 2009); $100 \%$ of costs paid by the beneficiary for drug spending falling in the coverage gap (between $\$ 2,700$ and $\$ 6,153.75$ in 2009 ); ${ }^{10}$ and all costs paid by program over the catastrophic threshold $(\$ 6,153.75$ in 2009$)$ except for nominal beneficiary cost-sharing. ${ }^{11}$ (See Figure 1 and Table 7.)

\footnotetext{
${ }^{9}$ Medicare Advantage plans are required to use $75 \%$ of the difference between the plan's benchmark payment and its bid for providing required Part A and Part B services (called the Part C rebate) to supplement its package of benefits or lower its premium. Many MA plans use some of their rebate dollars to enhance their Part D benefit or to reduce the portion of their plan premium associated with drug coverage.

${ }^{10}$ Also known as the "doughnut hole."

${ }^{11}$ Nominal cost sharing is defined as the greater of (1) a copayment of $\$ 2.40$ in 2009 for a generic drug or preferred multiple source drug and $\$ 6.00$ in 2009 for other drugs, or (2) 5\% coinsurance.
} 
Each year, the deductible, co-payments, and coverage thresholds are increased by the annual percentage increase in average per-capita aggregate expenditures for covered outpatient drugs for Medicare beneficiaries for the 12-month period ending in July of the previous year.

Figure I.Standard Medicare Prescription Drug Benefit, 2009

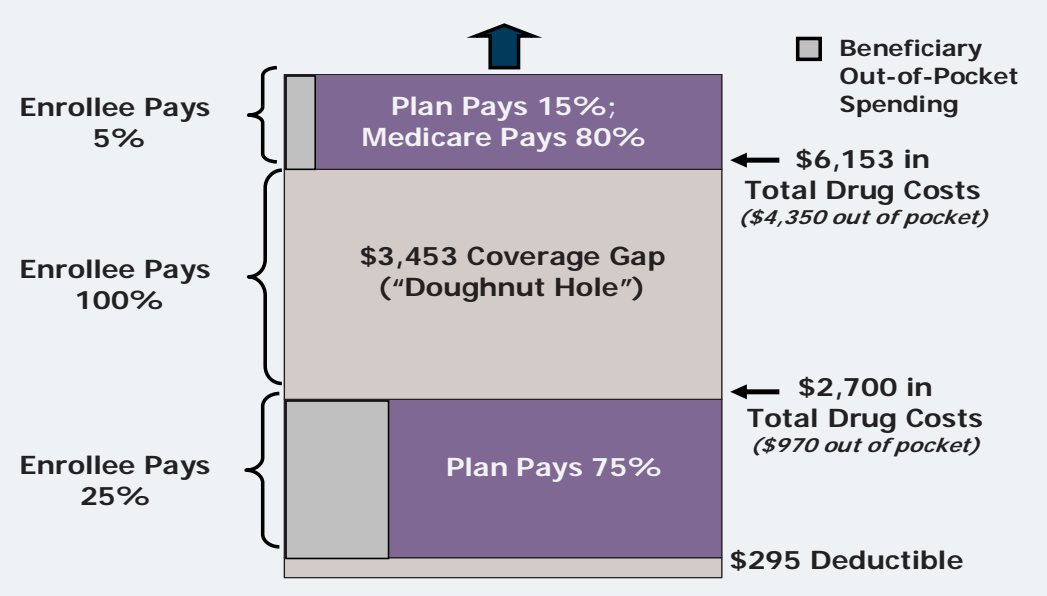

\$364 Average Annual Premium

Source: Kaiser Family Foundation, The Medicare Prescription Drug Benefit Fact Sheet, March 2009,

Notes: Annual premium amount based on $\$ 30.36$ national average monthly beneficiary premium. Amounts are rounded to nearest dollar.

\section{Alternative Prescription Drug Coverage}

Plans may offer different benefit structures, providing they have the same actuarial value as the standard benefit. For example, plans may eliminate the deductible but have cost-sharing requirements higher than the $25 \%$ amount under basic standard coverage. They may also use tiered cost-sharing - for example, design a benefit structure under which generics have lower cost-sharing than higher-cost brand-name drugs.

In 2009, only $10 \%$ of PDPs and 5\% of MA-PDs nationwide offered the standard drug benefit, ${ }^{12}$ while $37 \%$ of PDPs and $8 \%$ of MA-PDs offered plans that were actuarially equivalent. In 2008, $17 \%$ of PDP enrollees and 1\% of MA-PD enrollees were in defined standard benefit plans. In the same year, $61 \%$ of PDP enrollees and 6\% of MA-PD enrollees were enrolled in actuarially equivalent plans.

In $2009,55 \%$ of PDPs and $88 \%$ of MA-PDs offered plans with a zero deductible. ${ }^{13}$ The percentage of beneficiaries enrolled in a PDP with no deductible grew from $72 \%$ in 2006 to $75 \%$ in 2008, and for MA-PDs from $89 \%$ to $92 \%$.

\footnotetext{
${ }^{12}$ Medicare Payment Advisory Commission, "Report to Congress, Medicare Payment Policy," March 2009, Table 4-3. 13 Ibid.
} 


\section{Enhanced Coverage}

Plans may also offer enhanced coverage that exceeds the value of defined standard coverage. This coverage includes both basic coverage as well as some supplemental benefits that increase the actuarial value of the package. For example, these supplemental benefits may include reductions in cost sharing and/or some coverage in the coverage gap.

A PDP-sponsor cannot offer an enhanced plan unless it also offers a basic plan in the service area. MA organizations offering MA coordinated care plans are required to offer at least one plan in the service area with drug coverage. The drug coverage can be either basic coverage or enhanced coverage with no premium for the supplemental benefits.

In 2009, 53\% of PDPs offered enhanced coverage, while $88 \%$ of MA-PDs offered these types of plans. ${ }^{14}$ As of October 2008, 23\% of PDP enrollees were in enhanced plans, while $93 \%$ of MAPD enrollees were in such plans.

\section{The Coverage Gap}

A unique feature of the Medicare Part D drug benefit is the coverage gap-a period in coverage in which Part D enrollees are required to pay $100 \%$ of total drug costs until they reach the catastrophic coverage level. The coverage gap was included in the benefit structure because the cost of providing continuous coverage would have exceeded the budgetary limit when the program was established.

CMS estimates that $31.7 \%$ (8.3 million) of Part D enrollees reached the initial coverage limit of their drug plans in $2007 .{ }^{15}$ About $23.9 \%$ of non-LIS enrollees reached the initial coverage limit, compared with $43.7 \%$ of LIS enrollees. Approximately $36.3 \%$ of enrollees in PDPs (which include a large proportion of LIS enrollees) reached the coverage gap, compared with $21.3 \%$ of those in MA-PDs.

In 2009, nearly all Part D plans include a gap in coverage. The availability and generosity of gap coverage varies widely across Part D plans. About 25\% of PDPs (416 plans) offer some type of gap coverage (down from $29 \%$ in 2008). ${ }^{16}$ Approximately $51 \%$ of MA-PD plans offer some gap coverage (1,076 plans), the same share as in 2008 and twice the share of PDPs with gap coverage. Monthly premiums for PDPs that provide gap coverage are about double those of PDPs with no gap coverage in 2009. About $10.9 \%$ (2.9 million) of enrollees who reached the coverage gap were responsible for the full cost of their drugs, either because they were not LIS-eligible or they were not enrolled in plans with gap coverage.

\footnotetext{
14 Ibid.

${ }^{15}$ CMS, October 30, 2008, Medicare Prescription Drug Benefit Symposium, "Beneficiary Experience," http://www.cms.hhs.gov/PrescriptionDrugCovGenIn/08_PartDData.asp.

${ }^{16}$ Jack Hoadley et al., "Medicare Part D 2009 Data Spotlight: The Coverage Gap," Kaiser Family Foundation, November 2008.
} 
In 2009, as in previous years, the majority of plans offering gap coverage cover only generic drugs during the gap, and most cover only a subset of the generics listed in their formularies. Full gap coverage for brand-name and generic drugs does not currently exist in the PDP market. ${ }^{17}$

In addition to determining whether one is eligible to receive the low-income subsidy, CMS offers enrollees a number of other suggestions for avoiding or delaying the gap and for saving money while in the gap. These suggestions include switching to generic, ${ }^{18}$ over-the-counter, mail order, or other lower cost drugs when possible; looking at State Pharmaceutical Assistance Programs for which one may qualify; ${ }^{19}$ exploring national and community-based charitable programs that may offer assistance; and looking into Pharmaceutical Assistance Programs (also sometimes called Patient Assistance Programs) that may be offered by the manufacturers of the drugs taken. ${ }^{20}$ Additionally, CMS suggests that beneficiaries continue using their Medicare drug plan cards even when in the coverage gap. This helps to ensure that beneficiaries pay the drug plan's discounted negotiated prices and that out-of-pocket expenses count toward catastrophic coverage.

\section{Access to Negotiated Prices}

Part D plan sponsors (or the pharmaceutical benefit managers [PBMs] they have contracted with) negotiate prices with drug manufacturers, wholesalers, and pharmacies. ${ }^{21}$ All plans are required to provide beneficiaries with access to these negotiated prices for covered Part D drugs. This access must be provided even when no Part D benefits are payable because the beneficiary has not met the deductible or the beneficiary is in the coverage gap. Negotiated prices are to take into account negotiated price concessions for covered drugs. ${ }^{22}$ Such price concessions include discounts, direct or indirect subsidies, rebates, and other direct or indirect remunerations. The plan's negotiated price may reflect the same prices that a health plan or PBM would get for its commercially insured members, or it may be different.

The prices for drugs on a plan's formulary may be found on the www.medicare.gov website. Beneficiaries can also compare prices for different plans in their area. The net prices, including price concessions, charged to Part D plans by drug manufactures are reported to CMS; however, they are not made public.

\footnotetext{
${ }^{17}$ Initially, several sponsors offered full gap coverage but discontinued offering such coverage after experiencing significant adverse selection by high-cost enrollees.

${ }^{18}$ Part D sponsors are required to ensure that their network pharmacies inform enrollees of any price differential between a covered drug and the lowest-price generic version of the drug that is therapeutically equivalent, bioequivalent, on the plan's formulary, and available at that pharmacy.

${ }^{19}$ Some states offer payment assistance for drug plan premiums and/or other drug costs for individuals who have trouble affording their medication but do not qualify for LIS. For example, a state may offer assistance to individuals with incomes between $150 \%$ and $300 \%$ of the FPL. To learn which states offer this assistance and for details on the state programs, see http://www.medicare.gov/spap.asp.

${ }^{20}$ Many of the major drug manufacturers offer assistance programs for the drugs they manufacture. The value of the benefits received under these programs do not count toward true out-of-pocket expenses. To learn which manufacturers offer assistance, see http://www.medicare.gov/pap/index.asp.

21 The law prohibits the Secretary from interfering with the negotiations between drug manufacturers and pharmacies and PDP sponsors. See "Approval of PDP Plans" for further detail.

22 On January 12, 2009, CMS published a final rule (74 FR 1494) requiring Medicare Part D plan sponsors to use the amount paid to the pharmacy as the basis for determining cost sharing for beneficiaries and reporting a plan's drug costs to CMS. The changes must be implemented by the start of the 2010 plan year. Under current rules, Part D sponsors that contract with a PBM may report to CMS the amount paid to the PBM (the lock-in price) or the amount the PBM paid to the pharmacy (the pass-through price).
} 


\section{True Out-Of-Pocket (TrOOP) Expenses}

Under a standard plan design, beneficiaries must incur a certain level of out-of-pocket costs ( $\$ 4,350$ in 2009) before catastrophic protection begins. These include costs that are incurred for the deductible, cost-sharing, or benefits not paid because they fall in the coverage gap. Costs are counted as incurred, and thus treated as true out-of-pocket (TrOOP) costs only if they are paid by the individual (or by another family member on behalf of the individual), paid on behalf of a lowincome individual under the subsidy provisions, or paid under a State Pharmaceutical Assistance Program. Incurred costs do not include amounts for which no benefits are provided-for example, because a drug is excluded under a particular plan's formulary. Additional payments that do not count toward TrOOP include Part D premiums and coverage by other insurance, including group health plans, workers' compensation, Part D plans' supplemental or enhanced benefits, or other third parties.

\section{Premium Subsidies for Low-Income Populations}

Premium subsidies are available for both full-subsidy-eligible and other subsidy-eligible persons. The premium subsidy will vary based on the subsidy level for which the beneficiary qualifies.

\section{Full-Subsidy-Eligible Individuals}

Low-income beneficiaries who are eligible for the full premium subsidy may enroll in a benchmark plan without paying any premium. A Part D PDP qualifies as a "benchmark plan" if it offers basic Part D coverage with premiums equal to or lower than the regional low-income premium subsidy amount. (See "Availability of Low-Income Plans.") However, if a beneficiary selects a plan with a premium higher than the benchmark, the beneficiary is liable for the additional costs.

\section{Other Subsidy-Eligible Individuals}

Partial-subsidy-eligible individuals receive a sliding scale premium subsidy ranging from 100\% to $25 \%$ of the premium subsidy amount, as specified in Table 6.

Table 6. Sliding Scale Premium for Partial-Subsidy-Eligible Individuals

\begin{tabular}{lc}
\hline \multicolumn{1}{c}{ FPL and Assets } & $\begin{array}{c}\text { Percentage of Premium Subsidy } \\
\text { Amount }\end{array}$ \\
\hline $\begin{array}{l}\text { Income up to 135\% FPL, and with assets that do not exceed the calendar year } \\
\text { resource limits for individuals or couples. }\end{array}$ & $100 \%$ \\
Income above I35\% FPL but at or below I40\% FPL, and with assets that do not \\
exceed the calendar year resource limits for individuals or couples. \\
Income above 140\% FPL but at or below I45\% FPL, and with assets that do not \\
exceed the calendar year resource limits for individuals or couples. \\
Income above 145\% FPL but below I50\% FPL, and with assets that do not exceed the \\
calendar year resource limits for individuals or couples.
\end{tabular}

Source: Prescription Drug Benefit Manual, Chapter 13-Premium and Cost-Sharing Subsidies for Low-Income Individuals, Rev. 7, II-2I-08. 


\section{Cost-Sharing Subsidies for Low-Income Population}

Cost-sharing subsides for LIS enrollees are linked to the standard prescription drug coverage. Full-subsidy eligibles have no deductible, minimal cost sharing during the initial coverage period and coverage gap, and no cost-sharing over the catastrophic threshold. Additionally, full-benefit dual eligibles who are residents of medical institutions or nursing facilities have no cost-sharing. Other full-benefit dual-eligible individuals with incomes up to $100 \%$ of poverty have costsharing, for all costs up to the out-of-pocket threshold, of $\$ 1.10$ in 2009 for a generic drug prescription or preferred multiple source drug prescription and \$3.20 in 2009 for any other drug prescription. All other full-subsidy-eligible individuals have cost-sharing for all costs up to the out-of-pocket threshold, of $\$ 2.40$ in 2009 for a generic drug or preferred multiple source drug and $\$ 6.00$ in 2009 for any other drug (see Table 7).

Partial-subsidy-eligible individuals have a $\$ 60$ deductible in $2009,15 \%$ coinsurance for all costs up to the catastrophic trigger level, and cost-sharing for costs above this level of \$2.40 in 2009 for a generic drug prescription or preferred multiple source drug prescription and $\$ 6.00$ in 2009 for any other drug prescription. Each year, the cost-sharing amounts for full-benefit dual eligibles below $100 \%$ of poverty are increased by the increase in the Consumer Price Index. The costsharing amounts for all other beneficiaries, and the deductible amount for other subsidy eligible individuals, are increased by the annual percentage increase in per-capita beneficiary expenditures for Part D-covered drugs.

Table 7. Part D Standard Benefits, 2009

(by per capita drug spending category)

\begin{tabular}{|c|c|c|c|c|c|c|}
\hline \multirow{3}{*}{$\begin{array}{l}\text { Total drug } \\
\text { spending } \\
\text { (dollar } \\
\text { ranges) }\end{array}$} & \multirow{2}{*}{\multicolumn{2}{|c|}{ All Beneficiaries }} & \multicolumn{4}{|c|}{ Subsidy-Eligible Individuals } \\
\hline & & & \multicolumn{2}{|c|}{ Full-Subsidy Eligible } & \multicolumn{2}{|c|}{ Other Subsidy Eligible } \\
\hline & $\begin{array}{c}\text { Paid by Part } \\
\text { D }\end{array}$ & $\begin{array}{l}\text { Paid by } \\
\text { Enrollee }\end{array}$ & $\begin{array}{c}\text { Paid by Part } \\
\text { D }\end{array}$ & Paid by Enrollee & $\begin{array}{l}\text { Paid by } \\
\text { Part D }\end{array}$ & $\begin{array}{l}\text { Paid by } \\
\text { Enrollee }\end{array}$ \\
\hline $\begin{array}{l}\$ 0 \text { up to } \$ 295 \\
\text { Deductible }\end{array}$ & $0 \%$ & $\$ 295$ & $\$ 295$ & 0 & $\$ 235$ & $\$ 60$ \\
\hline $\begin{array}{l}\text { Between } \\
\text { Deductible and } \\
\text { Initial Coverage } \\
\text { Limit }(\$ 295.01 \text { - } \\
\$ 2,700)\end{array}$ & $75 \%$ & $25 \%$ & $\begin{array}{l}100 \% \text { less } \\
\text { enrollee cost- } \\
\text { sharing }\end{array}$ & $\begin{array}{l}\text { Institutionalized duals: } \\
\qquad 0 \\
\text { Duals under } 100 \% \text { of } \\
\text { poverty: } \$ 1.10 / \$ 3.20^{\mathrm{a}} \\
\text { Others: } \\
\$ 2.40 / \$ 6.00^{\mathrm{b}}\end{array}$ & $85 \%$ & $15 \%$ \\
\hline $\begin{array}{l}\text { Coverage } \\
\text { Gap } \\
\text { Between Initial } \\
\text { Coverage Limit } \\
(\$ 2,700.01) \text { and } \\
\text { Catastrophic } \\
\text { Trigger } \\
(\$ 6,153.75)\end{array}$ & $0 \%$ & $100 \%$ & $\begin{array}{l}100 \% \text { less } \\
\text { enrollee cost- } \\
\text { sharing }\end{array}$ & $\begin{array}{c}\text { Institutionalized duals: } \\
\$ 0 \\
\text { Duals under } 100 \% \text { of } \\
\text { poverty: } \$ 1.10 / \$ 3.20^{\mathrm{a}} \\
\text { Others: } \\
\$ 2.40 / \$ 6.00^{\mathrm{b}}\end{array}$ & $85 \%$ & $15 \%$ \\
\hline $\begin{array}{l}\text { Over } \\
\text { Catastrophic } \\
\text { Trigger } \\
(\$ 6,153.76 \text { and } \\
\text { over) }\end{array}$ & $95 \%$ & $5 \%$ & $100 \%$ & $\$ 0$ & $\begin{array}{c}100 \% \text { less } \\
\text { enrollee } \\
\text { cost } \\
\text { sharing }\end{array}$ & $\$ 2.40 / \$ 6.00^{b}$ \\
\hline
\end{tabular}


Source: CMS, Announcement of CY2009 Medicare Advantage Capitation Rates and Medicare Advantage and Part D Payment Policies, http://www.cms.hhs.gov/MedicareAdvtgSpecRateStats/Downloads/

Announcement2009.pdf.

a. $\$$ I.10 per prescription for generic or preferred drugs that are multiple source drugs; $\$ 3.20$ per prescription for other drugs.

b. $\$ 2.40$ per prescription for generic or preferred drugs that are multiple source drugs; $\$ 6.00$ per prescription for other drugs.

\section{Drug Coverage}

In order for a drug to be paid under Medicare's prescription drug benefit, it must be a drug that is covered under Part D and included in the formulary of an individual's Part D plan. The law defines covered Part D drugs as (1) outpatient prescription drugs approved by the Food and Drug Administration (FDA), and used for a medically accepted indication; (2) biological products that may be dispensed only upon a prescription and that are licensed under the Public Health Service (PHS) Act and produced at a licensed establishment; (3) insulin (including medical supplies associated with the injection of insulin); and (4) vaccines licensed under the PHS Act. Also included are drugs treated as being included in a plan's formulary as a result of a coverage determination or appeal.

A few drugs are excluded from Medicare coverage by law, including drugs specifically excluded from coverage under Medicaid. This exclusion applies to (1) benzodiazepines; (2) barbiturates; (3) drugs used for anorexia, weight loss, or weight gain; (4) fertility drugs; (5) drugs used for cosmetic purposes or hair growth; (6) drugs for symptomatic relief for coughs and colds;

(7) prescription vitamins and minerals; and (8) covered drugs when the manufacturer requires, as a condition of sale, that associated tests be purchased exclusively from the manufacturer. In addition, drugs used for the treatment of sexual or erectile dysfunction are excluded, unless they are used to treat another condition for which the drug has been approved by the FDA (off-label uses for these drugs are not covered). However, for prescriptions dispensed on or after January 1, 2013, plans will be required to include benzodiazepines in their formularies. Barbiturates will also be required to be included in the formularies for the indication of epilepsy, cancer, or chronic mental health disorder.

If a state covers these excludable drugs for Medicaid beneficiaries, then it also must cover them for dual eligibles when they are medically necessary. Dual eligibles may therefore receive coverage from Medicaid for some drugs excluded from Medicare. Additionally, a Part D sponsor may elect to include one or more of these drugs in an enhanced Part D plan; however, no federal subsidy is available for the associated costs.

\section{Drugs Covered by Other Parts of Medicare}

Part D drug plans are prohibited from covering drugs covered by other parts of Medicare. This includes prescription medications provided during a stay in a hospital or skilled nursing facility that are paid for by the Part A program, and in the limited circumstances when Part B covers prescription drugs. Part B-covered drugs include drugs that are not usually self-administered and are provided incident to a physician's professional services. These include such things as immunosuppressive drugs for persons who have had a Medicare-covered transplant; erythropoietin (anti-anemia drug) for persons with end-stage renal disease; oral anti-cancer drugs; 
drugs requiring administration via a nebulizer or infusion pump in the home; and certain vaccines (influenza, pneumococcal, and hepatitis B for intermediate- or high-risk persons).

\section{Formularies}

Prescription drug plans are permitted to operate formularies-lists of drugs that a plan chooses to cover and the terms under which they are covered. This means that plans can choose to cover some, but not all, FDA-approved prescription drugs.

A Part D sponsor's formulary must be developed and reviewed by a Pharmacy and Therapeutics Committee. The majority of the committee members are required to be practicing physicians or practicing pharmacists and must include clinical specialties that adequately represent the needs of beneficiaries. When developing and reviewing the formulary, the committee is to base clinical decisions on the strength of scientific evidence and standards of practice. It should also take into account whether including a particular drug in the formulary (or in a particular tier in the formulary) has therapeutic value in terms of safety and efficacy.

\section{Formulary Categories and Classes}

In developing a formulary, drugs are grouped into categories and classes of drugs that work in a similar way or are used to treat the same condition. MMA required CMS to request the United States Pharmacopeia (USP) to develop a list of categories and classes that plans may use and to periodically revise such classification as appropriate. A plan's formulary must include at least two drugs in each category or class used to treat the same medical condition (unless only one drug is available in the category or class, or two drugs are available but one drug is clinically superior). The two-drug requirement must be met through the provision of two chemically distinct drugs. (Plans cannot meet the requirement by including only two dosage forms or strengths of the same drug or a brand name and its generic equivalent.)

\section{Six Classes of Clinical Concern}

In general, drug plans are required to operate formularies that cover at least two drugs in each drug class. However, a higher standard of coverage has been established for six specific classes. CMS has required Part D plans to cover all, or substantially all, of the drugs in the following six drug categories: immunosuppressant, antidepressant, antipsychotic, anticonvulsant, antiretroviral, and antineoplastic. CMS instituted this policy to mitigate the risks and complications associated with a possible interruption of therapy for vulnerable populations. Plan sponsors cannot implement prior authorization or step therapy requirements (see "Utilization Management") that are intended to steer beneficiaries to preferred alternatives within these classes for beneficiaries currently taking a drug. ${ }^{23}$

Congress required in MIPPA that beginning in plan year 2010, CMS identify classes and categories of drugs that should be covered entirely by Part D plans to ensure that beneficiaries have access to certain life-saving therapies and to a wide variety of therapy options for certain conditions such as cancer (which may be different from the six classes currently required by

\footnotetext{
${ }^{23}$ For beneficiaries beginning treatment in these categories, such management techniques may be used for categories other than HIV/AIDS drugs.
} 
CMS). PDP sponsors will be required to include all covered Part D drugs in the categories and classes identified. CMS issued an interim final rule effective January 16, 2009, that will allow the agency to consider adding these protected classes of drugs to the Part D program. ${ }^{24}$

\section{Vaccines}

Starting in 2008, Medicare drug plans must include all commercially available vaccines on their drug formularies (except for vaccines that are covered under Part B). TRHCA modified the definition of a Part D drug to include "for [Part D] vaccines administered on or after January 1, 2008, its administration." Consequently, beginning in 2008, Part D plans (rather than Part B) are required to cover the costs for the administration of Part D-covered vaccines as well as the vaccine itself.

\section{Formulary Changes in a Plan Year}

Plans are allowed to change some of the drugs they cover during the year. MMA provided that if plans remove drugs from their formularies during the year (or change their preferred or tiered status), they are required to provide notice on a timely basis to CMS, affected enrollees, physicians, pharmacies, and pharmacists. Changes to formularies may be made in the following circumstances:

- Plans can expand formularies by adding drugs, lowering the tier of a drug (thereby reducing copayments or coinsurance), or deleting utilization management requirements.

- Plans may not change therapeutic categories and classes during a year except to account for new therapeutic uses and newly approved Part D drugs.

- Plans can make formulary maintenance changes after March 1, such as replacing a brand-name drug with a new generic drug or modifying formularies as a result of new information on safety or effectiveness. These changes require CMS approval and 60 days' notice to appropriate parties.

- Plans can only remove drugs from a formulary, move covered drugs to a lesspreferred tier status, or add utilization management requirements in accordance with approved procedures and after 60 days' notice to appropriate parties. ${ }^{25}$ Plans should make such changes only if enrollees currently taking the affected drugs are exempt from the formulary change for the remainder of the plan year.

\footnotetext{
${ }^{24} 74$ Federal Register 2881. Although the rule is effective for the 2010 plan year, CMS indicated that it would not make any changes to the current policy for protected classes of drugs until the 2011 plan year because it had too little time to establish the review process for adding protected classes and creating exceptions to those requirements.

The interim final rule also addresses a MIPPA-mandated change to the regulatory definition of "Part D drug," which expands the list of drug compendia CMS is to use to determine the medically accepted indications of anticancer therapies. It requires Part D sponsors to use the same definition for a "medically accepted indication" for anti-cancer drugs used for Medicare Part B, effective January 1, 2009.

${ }^{25}$ Plans may not remove covered Part D drugs from their formularies, or make any change in preferred or tiered costsharing status of a covered Part D drug, between the beginning of the annual coordinated election period and 60 days after the beginning of the contract year.
} 
Plans are not required to obtain CMS approval or give 60 days' notice when removing formulary drugs that have been withdrawn from the market by either the FDA or a product manufacturer.

\section{Transition Policies}

CMS established transition standards to ensure that new plan enrollees do not abruptly lose coverage for their drugs-for example, if a plan does not cover a drug a beneficiary is currently using. In such cases, a beneficiary can request that his or her physician check to see if the prescription can be switched to a similar drug that is on the plan's formulary, or if the physician determines that the specific drug is medically necessary, the doctor can request that the plan make an exception to its policy.

Plans are required to provide a temporary supply anytime within the first 90 days of a beneficiary's enrollment in a plan. The supply must be for 30 days (unless the prescription is written for less than 30 days) for any non-formulary drug. The requirement also applies to drugs that are on a plan's formulary but that require prior authorization or step therapy.

\section{Utilization Management}

Sponsors can lower their drug spending by applying various utilization management (UM) restrictions to drugs on their formularies. Sponsors must establish a reasonable and appropriate drug utilization management program that (1) includes incentives to reduce costs when medically appropriate and (2) maintains policies and systems to assist in preventing over-utilization and under-utilization of prescribed medications. Since 2006, the trend annually among plans has been to impose higher cost-sharing and utilization management controls to address the high costs of drugs.

\section{Tiered Formularies}

For drugs included on the formulary, sponsors may assign drugs to tiers that correspond to different levels of cost sharing. In general, this type of structure encourages the use of generic medications by putting them on a cost-sharing tier that requires the lowest out-of-pocket costs for beneficiaries and discourages the use of expensive drugs by putting them on tiers that require higher out-of-pocket spending. Plans have flexibility in how the tiers are structured, and different plans may place the same drug in different tiers; drugs in the parallel tiers may differ in costsharing requirements. To illustrate, a four-tier formulary may be structured so that Tier 1 includes low cost generics, Tier 2 includes medium-cost preferred brand-name drugs, ${ }^{26}$ Tier 3 contains higher cost non-preferred brand names, and very expensive or rare drugs are placed in Tier 4 (the "specialty tier").

Part D plans are permitted to use a specialty tier for expensive products (e.g., unique drugs and biologics). In this tier, there is no limit on cost-sharing and beneficiaries cannot appeal cost sharing for specialty tier drugs as they can for drugs in other tiers. Plans typically charge a percentage of the cost in the specialty tier. To ensure that the plan does not substantially

\footnotetext{
${ }^{26}$ Each plan negotiates the price of each drug with its manufacturer. If a plan obtains a good discount on one brandname drug, but not on a competing drug used in treating the same condition, the plan may charge a lower co-pay for the former (preferred) drug and a higher co-pay for the latter (non-preferred).
} 
discourage enrollment by specific patient populations, CMS will approve specialty tiers only under the following conditions: (1) there is only one specialty tier exempt from cost-sharing exceptions; (2) cost-sharing is limited to $25 \%$ in the initial coverage range, ${ }^{27}$ and (3) only drugs with negotiated prices exceeding a threshold may be placed in the tier ( $\$ 600$ a month in 2009).

A recent study found that the median cost share for generics in a PDP increased to $\$ 7$ for a month's supply of a drug in 2009, up from the $\$ 5$ it had been for previous years of the Part D benefit. ${ }^{28}$ Median cost sharing for preferred drugs in PDPs rose from \$28 in 2006 to \$38 in 2009; for non-preferred drugs over that same time period, it rose from $\$ 55$ to $\$ 75$. Medicare Advantage plans have seen fewer increases.

The percentage of PDPs that include a specialty tier has remained the same from 2006 to 2009, $82 \%$, while the percentage of MA-PDs with such a tier has increased from $69 \%$ in 2006 to $97 \%$ in 2009. Median cost sharing in this specialty tier has risen for both PDPs and MA-PDs, from $25 \%$ of the drug cost in 2006 to $33 \%$ in 2009.

\section{Other Drug Utilization Controls}

These types of restrictions can include (1) prior authorization, in which the beneficiary, with assistance of the prescribing physician, must obtain the plan's approval before it will cover a particular drug; (2) step therapy, which means that a beneficiary must first try a generic or lessexpensive drug to see if it works as well as the one prescribed; and (3) quantity limits, which limit the supply of drugs to the dosage or quantity it regards as normal to treat the condition, in order to reduce the likelihood of waste (e.g., the drug was not effective or had intolerable side-effects). For any of these utilization controls to be waived, a beneficiary's doctor needs to provide a statement indicating that the prescribed drug and dosage are medically necessary and to provide a rationale why the restriction is not appropriate.

PDPs are increasing their use of utilization management. ${ }^{29}$ The share of formulary drugs subject to UM tools increased from 18\% of listed drugs in 2007 to $26 \%$ in 2009 (number does not include tiering). Of the different types of UM tools, prior authorization increased from $8 \%$ to $12 \%$, quantity limits from $12 \%$ to $16 \%$, and step therapy from $1 \%$ to $3 \%$.

\section{Medication Therapy Management}

Each Part D Sponsor is required to incorporate a Medication Therapy Management Program (MTMP) into its plan's benefit structure, and each year, sponsors are to submit a description of its MTMP to CMS for review and approval. A CMS-approved MTMP is one of several required elements in the development of sponsors' bids for the upcoming contract year.

The MTMPs are to target enrollees who have chronic diseases, are taking multiple Part D drugs, and are likely to incur annual costs for covered drugs that exceed a level specified by the

\footnotetext{
${ }^{27}$ Sponsors may impose higher coinsurance in this tier to maintain actuarial equivalence in basic benefits (e.g., to offset a lower than standard deductible).

${ }^{28}$ Jack Hoadley et al., "Medicare Part D Benefit Designs and Formularies, 2006-2009," Presentation to MedPAC, December 5, 2008.

${ }^{29}$ Ibid.
} 
Secretary (\$4,000 in 2009 and $\$ 3,000$ in 2010). Beneficiaries enrolled in a MTMP cannot be disenrolled later in the year, even if they no longer meet one of the eligibility criteria. Plans are to provide interventions for beneficiaries meeting all of the criteria regardless of the setting.

An approved MTMP must (1) ensure optimum therapeutic outcomes for targeted beneficiaries through improved medication use; (2) reduce the risk of adverse events for targeted beneficiaries; (3) be developed in cooperation with licensed and practicing pharmacists and physicians; (4) be coordinated with any care management plan established for a targeted individual under a chronic care improvement program; and (5) describe the resources and time required to implement the program if using outside personnel and establish the fees for pharmacists or others. The MTMP may be furnished by pharmacists or other qualified providers.

\section{Coverage Determinations, Appeals, and Grievances}

As a beneficiary protection, Part D plans are required to have procedures in place for making timely coverage determinations, for handling appeals of coverage determinations, and for handling grievances. Beneficiaries can use the coverage determination and appeals process to challenge a utilization management restriction on a drug on the sponsor's formulary or to request coverage for a Part D drug that is not on the sponsor's formulary. The Medicare Part D program adapted many of the existing rules for grievance and appeals that apply to Medicare Advantage plans to prescription drug coverage.

CMS established priority levels for coverage determinations and appeal requests as either standard or expedited. Prescribing physicians may initiate coverage determinations and expedited redeterminations on behalf of a beneficiary without permission from the beneficiary, but to initiate a standard appeal on a beneficiary's behalf, the physician must have completed an appointment of representative form. Plans must ensure that all enrollees receive written information about these procedures.

\section{Coverage Determination}

A coverage determination is any decision (either an approval or denial) made by the plan sponsor with regard to covered benefits. Examples of coverage determinations include (1) a decision about whether to provide or pay for a Part D drug that the enrollee believes may be covered; ${ }^{30}$ (2) a decision concerning a tiering exceptions request; ${ }^{31} 3$ ) a decision concerning a formulary exceptions request; ${ }^{32}$ (4) a decision regarding the amount of cost-sharing; or (5) a decision on

\footnotetext{
${ }^{30}$ This includes a decision not to pay because the drug is not on the plan's formulary, the drug is determined not medically necessary, or the drug is furnished by an out-of-network pharmacy.

${ }^{31}$ MMA provided that if a Part D plan includes a tiered cost-sharing structure, a plan enrollee can request an exception to the structure. Under an exception, a non-preferred drug could be covered as a preferred drug if the prescribing physician determined that the preferred drug for treatment of the same condition would not be as effective for the individual, would have adverse effects for the individual, or both.

${ }^{32}$ MMA provided that a beneficiary enrolled in a Part D plan can appeal a determination not to provide coverage for a drug not on the plan's formulary. The appeal can only be made if the prescribing physician determines that all covered Part D drugs on any tier of the formulary for treatment of the same condition would not be as effective for the individual as the non-formulary drug, would have adverse effects for the individual, or both.
} 
whether an enrollee has satisfied a prior authorization or other utilization management requirement.

A request for a coverage determination may be filed by the enrollee, the enrollee's appointed representative, or the enrollee's physician. The sponsor must notify the enrollee of its determinations within 72 hours of receipt of the request (or, in the case of an exceptions request, receipt of the physician's supporting statement). Plans must respond to a standard appeal within seven days. An enrollee can request an expedited decision; if the plan approves the request, it must make the determination within 24 hours. If the sponsor fails to notify the beneficiary of its decision within the established time frames, the decision is deemed an automatic denial, at which point the sponsor must forward the case to the independent review entity, the second level of appeal.

\section{Appeals}

If the plan sponsor's coverage determination is unfavorable to the enrollee, it must provide the enrollee with a written denial notice that includes information on appeals rights. An appeal is a request to have further review of a coverage determination. ${ }^{33}$ There are five levels of appeals.

\section{Redetermination}

The first level of appeal is a redetermination by the plan. An enrollee, or an appointed representative, may request a standard or an expedited redetermination with respect to covered drug benefits or payments.

To request a redetermination, an individuals should write a letter to his/her plan asking for a redetermination of the decision not to cover a drug (or charge a higher level of cost-sharing). The letter should include the name of the drug that has been denied coverage, the reason for the denial, and reasons why the drug should be covered. The request should generally be filed within 60 days of the unfavorable coverage determination. The sponsor must provide the enrollee or prescribing physician with a reasonable opportunity to present evidence and the redetermination must be made by a person not involved in the original coverage determination. ${ }^{34}$ Enrollees are to be notified of the results within seven days in the case of standard redetermination or within 72 hours for an expedited request.

\section{Reconsideration by an Independent Review Entity}

At the second level of appeal, an enrollee dissatisfied with a redetermination has a right to reconsideration by an independent review entity (IRE) that contracts with CMS for this purpose. An enrollee or an enrollee's appointed representative may request a standard or expedited reconsideration. The request must be made within 60 days of the redetermination. An enrollee's prescribing physician may not request a reconsideration on an enrollee's behalf unless the enrollee's physician is also the enrollee's appointed representative; however, the IRE must solicit

\footnotetext{
${ }^{33}$ Individuals can appeal coverage determinations related to formulary drugs and non-formulary drugs. They cannot appeal denial of coverage for excluded drugs.

${ }^{34}$ If the issue is the denial of coverage based on medical necessity, the redetermination must be made by a physician.
} 
the views of the prescribing physician. It is required to make a decision within seven days for a standard reconsideration and 72 hours for an expedited reconsideration.

\section{Additional Levels of Appeal}

If the above appeals result in decisions unfavorable to the enrollee, several additional levels of review may be pursued.

At the third level of appeal, an enrollee or the appointed representative may request a hearing with an administrative law judge (ALJ). An enrollee's prescribing physician may not request a hearing by an ALJ on an enrollee's behalf unless the enrollee's physician is also the enrollee's appointed representative. The request must be made within 60 days of the IRE decision letter. To qualify for an ALJ hearing, the projected value of denied coverage must meet a minimum dollar amount (\$120 in 2009). No time frames are specified for ALJ action.

The fourth level of appeal is the Medicare Appeals Council (MAC). A beneficiary or the appointed representative may request a review by the MAC within 60 days of the ALJ decision. The MAC may grant or deny the request for review. If it grants the request, it may issue a final decision or dismissal, or remand the case to the ALJ with instructions on how to proceed with the case. No times frames are specified for a MAC review.

The final appeal level is a federal district court. A beneficiary or the appointed representative may request a review by a federal court within 60 days of the MAC decision notice. To receive a review by the court, the projected value of denied coverage must meet a minimum dollar amount $(\$ 1,220$ in 2009).

\section{Grievances}

Grievances are complaints or disputes other than those involving coverage determinations. Grievances may include such things as complaints about the plan's customer service hours of operation, time to obtain a prescription, or pharmacy charges. A grievance may also include a complaint that the Part D plan refused to expedite a coverage determination or redetermination. A beneficiary with a grievance should file the complaint within 60 days of the event. The plan sponsor must respond in a timely manner.

\section{Part D Plans: Payment and Participation}

Medicare Part D participants must obtain coverage through a private insurer, or other entity, that contracts with Medicare (a plan sponsor). As previously described, beneficiaries may select either a stand-alone prescription drug plan or a Medicare Advantage plan that includes prescription drug coverage along with other Medicare services. ${ }^{35}$

PDPs are required to be available regionwide within 1 of 34 Medicare-designated PDP regions in the United States. MA-PDs are generally local, operating on a countywide basis; however,

\footnotetext{
${ }^{35}$ The Part D sponsors are private entities licensed to offer health insurance under state law. Alternatively, they could meet solvency standards established by CMS for entities not licensed by the state.
} 
regionwide MA-PDs are available in 22 of the 26 MA regions. A PDP sponsor may offer a PDP in more than one region, including all PDP regions; however, the sponsor must submit separate bids for its coverage in each region of its service area. ${ }^{36}$

Medicare's payments to plans are determined through a competitive bidding process, and enrollee premiums are tied to plan bids. Plans bear some risk for their enrollees' drug spending.

\section{Approval of PDP Plans}

Each year, CMS issues a call letter to sponsors planning to offer PDP and/or MA plans in the coming year. The 2009 call letter, issued in March 2008, combined contracting guidance for both programs. $^{37}$

Potential PDP and MA sponsors are required to submit bids by the first Monday in June of the year prior to the plan benefit year. The following information must be included with the bid: (1) coverage to be provided; (2) actuarial value of qualified prescription drug coverage in the region for a beneficiary with a national average risk profile; (3) information on the bid, including the basis for the actuarial value, the portion of the bid attributable to basic coverage and, if applicable, the portion attributable to enhanced coverage, and assumptions regarding the reinsurance subsidy; and (4) service area. The bid also includes costs (including administrative costs and return on investment/profit) for which the plan is responsible. The bid must exclude costs paid by enrollees, payments expected to be made by CMS for reinsurance, and any other costs for which the sponsor is not responsible.

CMS reviews the information to conduct negotiations with the sponsors regarding the terms and conditions of the proposed bid and benefit plan and determines whether to approve the plan sponsor's bid submission. MMA specified that the Secretary's negotiating authority is similar to the authority the Director of the Office of Personnel Management has with respect to Federal Employees Health Benefits (FEHB) plans. However, the law specifically states that the Secretary may not interfere with the negotiations between drug manufacturers and pharmacies and PDP sponsors. Further, the Secretary may not require a particular formulary or institute a price structure for the reimbursement of covered Part D drugs. This is known as the "non-interference provision.",38

CMS can approve a plan only if certain requirements are met. For example, CMS must determine that the plan and the sponsor meet requirements relating to actuarial determinations and beneficiary protections. Further, the plan is not to be designed in a way (including any formulary and tiered formulary structure) that would be likely to discourage enrollment by certain beneficiaries.

\footnotetext{
${ }^{36}$ If two or more plans are not available in a region (one of which is a PDP), Medicare is required to contract with a non-risk "fallback" plan to serve beneficiaries in that area. Because of the large number of Part D plans participating in the program, CMS has not needed to solicit bids from fallback contractors.

${ }^{37}$ See http://www.cms.hhs.gov/PrescriptionDrugCovContra/Downloads/CallLetter.pdf. The 2010 call letter was issued March 30, 2009, and contains guidance to plans that will be submitting bids for the 2010 plan year; http://www.cms.hhs.gov/PrescriptionDrugCovContra/Downloads/2010CallLetter.pdf

${ }^{38}$ Social Security Act $§ 1860 \mathrm{D}-11(\mathrm{i})$.
} 
Once their bids have been approved, PDP sponsors enter into 12-month contracts with CMS. The contract may cover more than one Part D plan. Under the terms of the contract, the sponsor agrees to comply with Part D requirements and have satisfactory administrative and management arrangements.

\section{Plan Availability}

In 2007 and 2008, most beneficiaries were able to choose from 50 to 60 PDPs options. However, in 2009, the total number of PDPs available in each region declined to a median of 49 (1,689 total number of PDPs in 2009 compared with 1,824 in 2008). ${ }^{39}$ (See Figure 2.). The decline is due to organizational mergers and acquisitions as well as withdrawals of certain benefit designs. For example, UnitedHealthcare and PaciCare merged in 2006 and reduced the number of combined plans over a three-year period. Additionally, several organizations-including Sterling, Longs Drug Stores, and Coventry-withdrew PDPs from the market that covered generic drugs for beneficiaries whose spending had reached the coverage gap.

Figure 2. Prescription Drug Plans Available by Region, 2009

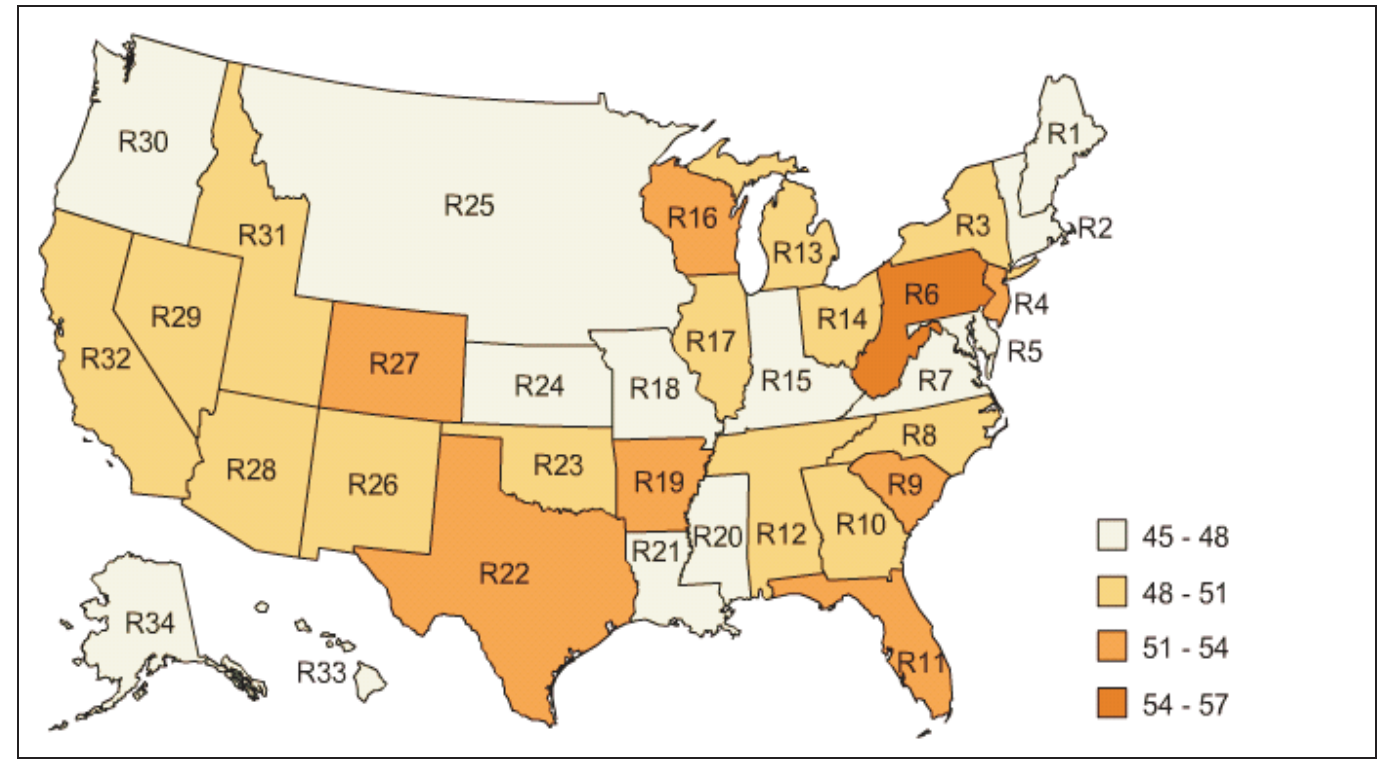

Source: Kaiser Medicare Health and Prescription Drug Plan Tracker, data from Mathematica Policy Research analysis of CMS Prescription Drug Plan Landscape file.

In 2006 and 2007, Part D enrollment in PDPs was concentrated among a relatively small number of sponsors, with two organizations, UHC-PacifiCare and Humana, capturing nearly half of all Part D PDP enrollees. In 2008, these companies were still dominant, but their market shares declined to a combined $41 \%$ of the 17.4 million members in the PDP market because of reassignments of LIS enrollees to lower-premium plans. The third largest PDP sponsor in 2008, Universal American, accounted for 11\% of enrollment. In 2008, 16 organizations that offered one or more PDPs in each of the 34 regions continued to account for $86 \%$ of PDP enrollment.

\footnotetext{
${ }^{39}$ Medicare Payment Advisory Commission, “Report to Congress, Medicare Payment Policy,” March 2009.
} 
The number of MA-PDs offered in 2009 increased to 2,039 plans from 1,932 in $2008 .{ }^{40}$ For MAPDs, the same two organizations that had the largest PDP membership, United Healthcare and Humana, also had the greatest market shares of enrollment in MA plans that offer drug benefits, with United Healthcare accounting for $17 \%$ and Humana for $15 \%$ of the 8.6 million members in MA-PDs in 2008 (the same percentage as 2007).

\section{Availability of Low-Income Plans}

A Part D plan qualifies as a benchmark plan if it offers basic Part D coverage with premiums equal to or lower than the regional low-income premium subsidy amount. The regional lowincome benchmark premium amount, calculated annually, is the weighted average of all premiums in each of the 34 prescription drug plan regions for basic prescription drug coverage, or the actuarial value of basic prescription drug coverage for plans that offer enhanced coverage options, or for Medicare Advantage Prescription Drug plans (MA-PD), the portion of the premium attributable to basic prescription drug benefits.

As a result of annual changes in the regional benchmarks and changes in Part D plan offerings, the overall number of LIS benchmark plans has declined from 483 plans ( $26 \%$ of all plans offered) in 2007 to 308 plans (18\%) in $2009 .{ }^{41}$ LIS beneficiaries who were enrolled in a benchmark plan that no longer qualified in 2009 were either auto-enrolled in a new plan or needed to make a new plan selection in order to avoid paying premiums and other cost-sharing requirements. See Figure 3, "Premium Subsidies for Low-Income Populations," and "LIS Enrollment."

${ }^{40}$ Ibid.

${ }^{41}$ Laura Summer et al., "Medicare Part D 2009 Data Spotlight: Low-Income Subsidy Plan Availability,” Kaiser Family Foundation, November 2008. 
Figure 3. Low-Income Subsidy Eligible Prescription Drug Plans, 2009

by Prescription Drug Plan Region

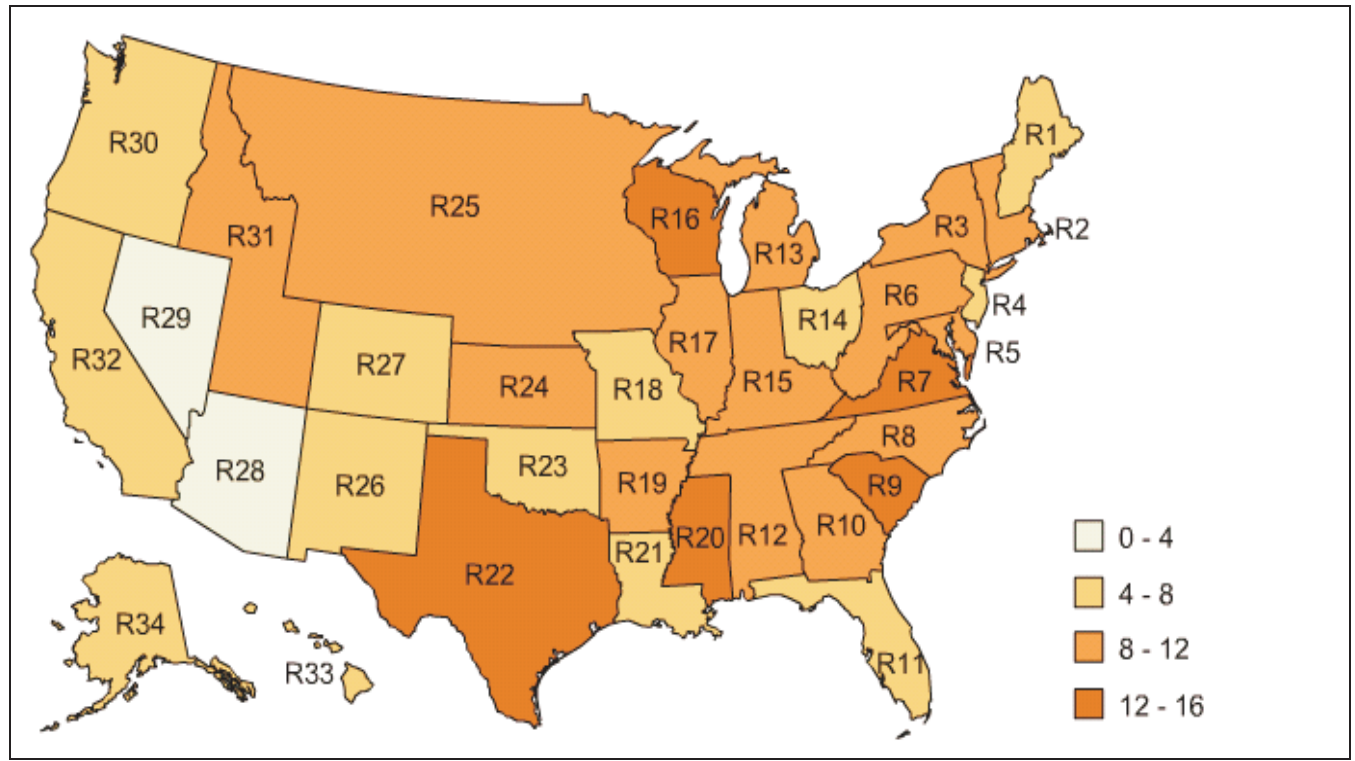

Source: Kaiser Medicare Health and Prescription Drug Plan Tracker, data from Mathematica Policy Research analysis of CMS Prescription Drug Plan Landscape file.

\section{Notes:}

- Refers to plans that have no additional premium when the full low-income subsidy is applied. These plans are eligible for auto-enrollment of dual eligibles and facilitated enrollment of those found eligible for lowincome subsidies.

- Two LIS benchmark plans are available in Arizona (R28) and one in Nevada (R29).

\section{Plan Payments}

For each Medicare enrollee in a plan (either stand-alone PDP or MA-PD), Medicare provides plans with a subsidy that averages $74.5 \%$ of standard coverage. The average subsidy takes two forms: direct subsidy payments and reinsurance payments. Medicare also establishes risk corridors to limit a plan's overall losses or profits. In addition, Medicare pays plans that enroll low-income beneficiaries most of their enrollees' cost sharing and premiums. Although plans receive essentially the same level of direct subsidy per enrollee (modified by risk adjusters), the level of subsidies granted through the other mechanisms differs substantially from plan to plan.

\section{Direct Subsidies}

Medicare makes monthly prospective payments to plans for each Part D enrollee. The payment is based on the nationwide average of plan bids for provision of basic drug coverage, ${ }^{42}$ weighted by the plan's share of total enrollment. ${ }^{43}$ (The national average monthly bid amount was $\$ 84.33$ for

\footnotetext{
${ }^{42}$ The calculation of the national average monthly bid amount does not include bids submitted by Medical Savings Account (MSA) plans, MA private fee-for-service plans, specialized MA plans for special needs populations (SNP), Program of All-Inclusive Care for the Elderly (PACE) plans, or plans established through reasonable cost contracts.

${ }^{43}$ In 2006, the first year of Part D, there was no prior PDP enrollment information; therefore, each PDP plan was (continued...)
} 
plan year 2009. ${ }^{44}$ This amount is then risk-adjusted to take into account the health status of beneficiaries expected to enroll-plans with sicker enrollees receive a higher subsidy. The subsidy is further adjusted to cover expected additional costs associated with low-income enrollees (the low-income subsidy). Lastly, the payment amount is reduced by the base beneficiary premium for the plan. ${ }^{45}$ (See "Premiums.")

\section{Reinsurance Subsidies}

As previously noted, in a standard plan design, Part D plans pay all drug costs above the catastrophic threshold (\$6,154 in 2009) except for nominal beneficiary cost sharing. Medicare subsidizes $80 \%$ of the plans' costs for catastrophic coverage. Payments are made on a monthly basis during the year based on either estimated or incurred costs, with final reconciliation made after the close of the year.

\section{Risk Corridor Payments}

MMA established risk corridors to limit plans' overall risks or profits under the new program. Under risk corridors, Medicare limits a plan's potential losses, or gains, by financing some of the higher than expected costs, or recouping excessive profits.

Risk corridors are defined as specified percentages above and below a target amount and are set separately for each plan. The target amount is based on the total risk-adjusted subsidy payments paid to the plan plus beneficiary premiums, reduced by the administrative expenses assumed in the bid. The target amount is then compared to the plan's actual allowable costs. ${ }^{46}$ If actual costs exceed the target amount, Medicare reimburses plans for a portion of their losses, and if costs are lower than the target, the sponsor may owe money to CMS.

Over time, as more experience has been gained with the program, the risk corridors have widened, thereby increasing the insurance risk borne by the plans. From 2008 to2011, drug plans bear all gains and losses that fall within 5\% of their expected costs, compared with $2.5 \%$ in 2006 and 2007 (see Table 8). Beginning in 2012, CMS may widen the risk corridors further.

\footnotetext{
(...continued)

weighted equally (though MA-PD bids were enrollment-weighted if they had 2005 MA enrollment). Rather than immediately moving to full enrollment weighting in 2007, CMS provided for a phase-in under its demonstration authority. In $2007,80 \%$ of the national monthly bid amount was based on the 2006 averaging methodology and $20 \%$ on the enrollment-weighted average. In 2008, 40\% was based on the 2006 averaging methodology and $60 \%$ on the enrollment-weighted average. In 2009 and thereafter, the national bid amount is fully weighted by plan enrollment.

${ }^{44}$ The national average monthly bid amount was $\$ 80.43$ for plan year 2007 and $\$ 80.52$ for 2008 .

${ }^{45}$ CMS takes plans' standardized bid amounts for basic benefits or the portion of plan bids attributable to basic coverage and calculates the average. From this nationwide average, plan enrollees must pay a base premium ( $\$ 30.36$ in 2009) plus any difference between their plan's bid and the nationwide average bid.

${ }^{46}$ Allowable costs include Part D drug costs minus the reinsurance subsidy and direct and indirect remuneration from drug manufacturers.
} 
Table 8. Plan Liability Under Risk Corridor Provisions

\begin{tabular}{|c|c|}
\hline Risk Corridor & Plan Liability for Costs Above and Below Target \\
\hline \multicolumn{2}{|l|}{ 2006-2007 } \\
\hline Costs below $95 \%$ of target & $80 \%$ refund \\
\hline Costs between $95 \%$ and $97.5 \%$ of target & $75 \%$ refund \\
\hline Costs between $97.5 \%$ and $102.5 \%$ of target & Full risk \\
\hline Costs between $102.5 \%$ and $105 \%$ of target & Risk for $25 \%$ of amount \\
\hline Costs over $105 \%$ of target & Risk for $20 \%$ of amount \\
\hline \multicolumn{2}{|l|}{ 2008-20 I I } \\
\hline Costs below $90 \%$ of target & $80 \%$ refund \\
\hline Costs between $90 \%$ and $95 \%$ of target & $50 \%$ refund \\
\hline Costs between $95 \%$ and $105 \%$ of target & Full risk \\
\hline Costs between $105 \%$ and $110 \%$ of target & Risk for $50 \%$ of amount \\
\hline Costs over $110 \%$ of target & Risk for $20 \%$ of amount \\
\hline
\end{tabular}

\section{Reconciliation}

Following the close of the calendar year, CMS makes retroactive adjustments to the direct subsidy payments made to plans to reflect actual plan experience. To illustrate, the direct subsidy payments are adjusted based on updated data about actual beneficiary health status and enrollment. Additionally, prospective payments for reinsurance and low-income subsidy payments are compared to actual incurred costs, net of any direct or indirect remuneration (including discounts, chargebacks or rebates), and other related data, and appropriate adjustments are made to the plan payments. Finally, any necessary adjustments are made to reflect risk sharing under the risk corridor provisions.

In October 2007, CMS announced that it would collect $\$ 4$ billion from Part D drug plan sponsors for the 2006 plan year because actual drug costs for almost all Part D plans were lower than the costs estimated in their 2006 bids. The 2007 bid submissions, which reflected the actual 2006 Part D program experience, were significantly lower than those submitted in 2006. Part D drug plan sponsors will return a net $\$ 18$ million to CMS as part of the 2007 reconciliation process. ${ }^{47}$ Not all insurers owed money back to the government, and some received additional payments because of higher than expected costs.

\footnotetext{
${ }^{47}$ For 2007, UHC-Pacificare again owes the largest amount to CMS (\$590 million in 2007 and \$2 billion in 2006).
} 


\section{Enrollment in Part D}

\section{Enrollment Periods}

A beneficiary who is signing up for Medicare Part D for the first time may do so in one of three different enrollment periods, depending on the individual's circumstances:

- Initial Enrollment Period for Part D.

- Annual Open Enrollment Period (or Annual Coordinated Election Period, AEP).

- Special Enrollment Periods (SEP).

\section{Initial Enrollment Period}

The initial enrollment period is the time during which an individual is first eligible to enroll in a Part D plan. Beneficiaries not yet enrolled in Medicare who have no other "creditable" coverage may join a drug plan at any time during their seven-month initial Medicare enrollment period. Creditable coverage is prescription drug coverage that is expected to cover at least as much as Medicare's standard prescription drug coverage. ${ }^{48}$ This initial enrollment period is the same as that applicable for Medicare Part B. Coverage for these individuals begins on the first day of the month following the month of enrollment, but no earlier than the first month they are entitled to Medicare.

\section{Annual Open Enrollment Period}

In general, an individual who does not enroll during his or her initial enrollment period may enroll only during the annual open enrollment period, which occurs from November 15 to December 31 each year. Coverage begins the following January 1. Beneficiaries already enrolled in a Part D plan may change their plans during the annual open enrollment period.

Beneficiaries may wish to change PDP plans for a variety of reasons, including changes in their health and prescription drug needs or modifications by their plans. Generally, sponsors make changes to benefits offered by their plans effective at the beginning of each benefit year. After the opportunity to change plans during the AEP, most beneficiaries enrolled in Part D plans are locked into their plans for the benefit year.

\section{Special Enrollment Periods}

There are a few additional, limited occasions when an individual may enroll in or disenroll from a Part D plan or switch from one Part D plan to another, called special enrollment periods (SEPs). For example, SEPs are allowed for individuals who (1) move to a new geographic area, (2) involuntarily lose creditable coverage, (3) receive inadequate information on creditable

\footnotetext{
${ }^{48}$ Sources of possible creditable coverage include some employer-based prescription drug coverage, including the Federal Employees Health Benefits Program; qualified State Pharmaceutical Assistance programs (SPAPs); militaryrelated coverage (e.g., VA, TRICARE); and certain Medicare supplemental (Medigap) policies.
} 
coverage status, (4) are subject to a federal error, or (5) are enrolled in a PDP that has failed or been terminated.

\section{Late Enrollment Penalty}

The late enrollment penalty is assessed on persons who go for 63 days or longer after the close of their initial Part D enrollment period without creditable coverage and subsequently enroll in Part D. The penalty is intended to encourage all persons who do not have creditable coverage to enroll to prevent adverse selection. Adverse selection occurs when only those persons who think they need the benefit actually enroll in the program. When this happens, per capita costs can be driven up, thereby causing more persons (presumably the healthier, less costly ones) to drop out of the program. Over time, as more persons drop out, program costs could become prohibitive.

The penalty is based on the number of months an individual does not have creditable coverage. ${ }^{49}$ For 2009, the penalty is based on $1 \%$ per month without creditable coverage of the 2009 national base premium (\$30.36). As an example, if a beneficiary were eligible for Part D in June 2006, 31 months from January 2009 , the individual would owe $\$ 9.41$ per month more than if he or she had signed up in June 2006. The penalty would be applied permanently. For beneficiaries whose premium is withheld from Social Security benefits, the Social Security Administration increases the withhold amount by the amount of the penalty. For plan members in direct-bill status, the Part D plan sponsor is required to bill the beneficiary for the penalty at the same time that it bills for his or her Part D plan premium; the beneficiary may pay the penalty on a monthly basis or any other billing cycles offered by the plan. Dual-eligible beneficiaries or individuals who have qualified for the LIS program are not subject to the late enrollment penalty.

\section{Plan Selection}

Plans can make a number of changes to their benefit structures from one year to the next, including changing drugs included in the plan's formulary and/or changing the required costsharing charges for certain drugs. CMS requires that sponsors mail enrollees an Annual Notice of Change (ANOC) for receipt by October 31. This document describes modifications to the plan's premium, drug coverage, cost sharing, and other features for the next benefit year. This schedule provides beneficiaries with at least two weeks to review the ANOC prior to November 15, the first day plans can accept AEP enrollments.

In addition, sponsors are required to send beneficiaries other enrollment-related materials and information such as the Evidence of Coverage, a Summary of Benefits, a document describing the formulary, the plan's general utilization management policies and procedures, and a chart of covered drugs that includes the drug's name, tier placement, and any utilization management restrictions.

Each year, Medicare beneficiaries should review the costs for their current drug and health plans, (if in MA) including premiums, co-pays, and deductibles, and compare the cost and coverage to other plans in their area. Additionally, beneficiaries should consider in what tier the drugs are placed and what, if any, utilization management requirements the plan imposes for those drugs.

\footnotetext{
${ }^{49}$ The late enrollment penalty is calculated based on the national base beneficiary premium, not the plan's premium. Therefore, the penalty is billed to applicable members even if the plan's Part D basic premium is $\$ 0$.
} 
Information regarding and links to resources to compare the costs or benefits of Medicare prescription drug plans may be found on CMS's Open Enrollment Web page. ${ }^{50}$ Additionally, beneficiaries and persons assisting them can help find a plan by using the Medicare drug plan finder. ${ }^{51}$ After entering information on all the medications and dosages of each that the beneficiary currently takes, the plan finder shows the beneficiary the five plans in the area with the lowest total annual cost for that package of drugs. ${ }^{52}$ The drug plan finder also provides an overall summary score of each drug plan's performance to make it easier to compare drug plans based on cost, quality, and performance ratings. ${ }^{53}$

Information on plan availability and characteristics can be obtained from a number of additional sources, including the Medicare toll-free information number (1-800-MEDICARE), State Health Insurance Assistance Programs (SHIPs), ${ }^{54}$ and other local organizations.

Despite the potential for cost increases or changes in drug coverage from year to year, the vast majority of enrollees do not switch their drug plans. According to MedPAC, since the program began in 2006 , only about $6 \%$ of enrollees have switched plans voluntarily each year. ${ }^{55}$

\section{Plan Marketing}

Plan sponsors are required to ensure timely and accurate information in their marketing materials. In developing these materials for the 2009 open enrollment period, sponsors could choose to adopt CMS's model documents or to create non-model documents that contain CMS's required elements. Sponsors are required to submit all annual enrollment marketing materials to CMS for review prior to mailing to enrollees. In its 2009 call letter to plans, ${ }^{56} \mathrm{CMS}$ emphasized that as marketing is the primary means for organizations to attract people with Medicare to their products, providing accurate and reliable information is essential to helping inform beneficiaries of their choices. Therefore, organizations must provide training to marketing representatives on Medicare rules, regulations, and compliance-related information on the plan products they intend to sell.

\footnotetext{
${ }^{50}$ http://www.cms.hhs.gov/center/openenrollment.asp.

${ }^{51} \mathrm{http}: / / \mathrm{www}$. medicare.gov/my-medicare-tools.asp.

${ }^{52}$ For example, a plan with the lowest premium and/or no deductible may end up not being the lowest cost plan for the beneficiary if the costs for the beneficiary's drugs are more than under a different plan.

${ }^{53}$ The plans are rated on how well they perform in four different categories, including (1) drug plan customer service, (e.g., how long members wait on hold and how frequently they meet deadlines for timely appeals); (2) member complaints and number of beneficiaries staying with the same drug plan; (3) member satisfaction with drug plans; and (4) drug pricing and patient safety, including how often drug plans update their prices and formulary information on the Medicare website and how similar a drug plan's estimated prices on the Medicare website are to prices members pay at the pharmacy. The ratings range from one to five stars, with one star meaning "poor" and five starts meaning "excellent."

${ }^{54}$ SHIPs are state-based programs that use community-based networks to provide Medicare beneficiaries with local personalized assistance on a wide variety of Medicare and health insurance topics and receive federal funding for their activities. See http://www.medicare.gov/Contacts/static/allstatecontacts.asp.

${ }^{55}$ Medicare Payment Advisory Commission, "Report to Congress, Medicare Payment Policy," March 2009.

${ }^{56}$ http://www.cms.hhs.gov/PrescriptionDrugCovContra/Downloads/CallLetter.pdf.
} 
On September 18, 2008, CMS published a final rule implementing certain MA and PDP marketing provisions in MIPPA. ${ }^{57}$ Specifically, the rule prohibits plans from providing meals to prospective enrollees at promotional events; prohibits plans from cross-selling non-health carerelated products during Medicare marketing activities; prohibits unsolicited contact with potential enrollees (e.g., door-to-door solicitation); restricts marketing activities in provider offices; requires that only state-licensed representatives conduct marketing activities; and defines certain terms related to marketing activities. The rule was effective September 18, 2009, and first applied to the 2009 benefit year marketing campaign.

A second rule, issued the same day, ${ }^{58}$ addresses a variety of other MIPPA MA and Part D provisions and is subject to a public comment period. With regard to Part D and MA marketing, the rule, among other things, codifies the $\$ 15$ limit on nominal gifts to prospective enrollees; codifies restrictions on co-branding; limits marketing appointments to the scope of health carerelated products agreed upon by the beneficiary in advance; restricts agent/broker compensation arrangements to reduce financial incentives to move a beneficiary from one plan to another; and establishes requirements for agent/broker training and testing and the reporting of terminated agents/brokers.

\section{Enrollment Process}

Beneficiaries can join a Medicare drug plan in a variety of ways, including (1) filling out a paper application; (2) visiting the plan's website and enrolling online; (3) using the Medicare online enrollment center at www.medicare.gov; ${ }^{59}$ (4) calling the company offering the drug plan; and (5) calling 1-800 Medicare. In general, a PDP sponsor cannot deny a valid enrollment request from any Part D-eligible individual residing in its service area.

An individual (or his/her legal representative) must complete an enrollment request, include all the information required to process the enrollment, and submit the request during a valid enrollment period. Upon receiving an enrollment request, a PDP sponsor must provide within 10 calendar days (1) a notice of acknowledgement of receipt of the beneficiary's application, (2) a request for more information in cases of incomplete applications, or (3) a notice that the application has been denied, along with an explanation of the reasons.

Prior to the effective date of enrollment, the PDP sponsor must provide the member with all the necessary information about being a Medicare member of the PDP, including the PDP rules and the member's rights and responsibilities. In addition, the PDP sponsor must provide the following: a copy of the completed enrollment form, if needed; a notice acknowledging receipt of the enrollment request providing the expected effective date of enrollment; and proof of health insurance coverage so that the beneficiary may begin using the plan services as of the effective date. For all enrollment requests, the PDP sponsor must submit the information necessary for CMS to add the beneficiary to its records as an enrollee of the PDP sponsor within seven calendar days of receipt of the compete enrollment request. ${ }^{60}$

\footnotetext{
5773 Federal Register 54208.

5873 Federal Register 54226.

${ }^{59}$ Medicare drug plan participation in Medicare's enrollment center is voluntary, so not all Medicare drug plans will offer this option.

${ }^{60}$ In a December 2008 report, GAO found that about $15 \%$ of beneficiaries who chose to switch plans in the 2008 AEP (continued...)
} 


\section{LIS Enrollment}

Special enrollment rules apply to low-income persons. Generally, there is a two-step process for low-income persons to gain Part D coverage. First, a determination must be made that they qualify for the assistance; second, they must enroll, or be enrolled, in a specific Part D plan. Most beneficiaries receiving low-income subsidies, including dual eligibles and nursing home residents, are permitted to switch plans throughout the year, unlike other Part D enrollees who generally may switch plans only during the annual enrollment period at the end of the year.

\section{Auto-Enrollment}

Full-benefit dual-eligible individuals who have not elected a Part D plan are auto-enrolled into one by CMS.$^{61}$ First, CMS uses data provided by state Medicaid agencies to identify full-benefit dual-eligible individuals. Then, CMS identifies plan sponsors that offer at least one Part D plan in the region offering basic prescription drug coverage with a premium at or below the low-income premium subsidy amount in each PDP region. If more than one sponsor in a region meets the criteria, CMS auto-enrolls the beneficiary on a random basis among available PDP sponsors. CMS then identifies the individual plans offered by the sponsor that include basic drug coverage with premiums at or below the low-income premium subsidy amount. The beneficiary is then randomly assigned among the sponsor's plans meeting that criteria.

If the individual is not eligible to enroll in a PDP because he or she is enrolled in a Medicare Advantage plan (other than a MA-PFFS plan that does not offer Part D, or an MSA plan), CMS will direct the MA organizations to facilitate the enrollment of these individuals into an MA-PD plan offered by the same MA organization.

Some dual eligibles may find that they are auto-enrolled in a plan that may not best meet their needs. For this reason, they are able to change enrollment at any time, with the new coverage effective the following month. If an enrollee selects a plan with a premium above the low-income benchmark, he or she is required to pay the difference.

\section{Facilitated Enrollment}

CMS established a process labeled "facilitated enrollment" for enrollees in Medicare Savings programs (MSPs), SSI enrollees, and persons who applied for and were approved for low-income subsidy assistance. The basic features applicable to auto-enrollment for dual eligibles (i.e., identification of eligibility through SSA and/or Medicaid data, random assignment to plans with premiums below the low-income benchmark, and assignment of MA enrollees to the lowest-cost MA-PD plan offered by the MA organization) are the same for facilitated enrollment.

(...continued)

were not fully enrolled in their new plan by January 1, due largely to the volume of applications submitted late in the AEP. As a result, beneficiaries, pharmacies, and sponsors faced various operational challenges, including the risk of inaccurate charges and additional administrative burden; "Medicare Part D: Opportunities Exist for Improving Information Sent to Enrollees and Scheduling the Annual Election Period", GAO-09-4, December 12, 2008.

${ }^{61}$ Full-benefit duals who live in another country, live in one of the five U.S. territories, are inmates in a correctional facility, have already enrolled in a Part D plan, or have opted out of auto-enrollment into a Part D plan are excepted from this process. 


\section{Reassignment of Certain LIS Beneficiaries}

Because CMS subsidizes up to a specific premium amount for LIS-eligibles, and plan premiums may change each year, CMS may need to reassign some LIS recipients to different plans so they can continue to receive drug benefits with no or low Part D premiums. In 2009, 1.6 million lowincome beneficiaries were reassigned to new plans. ${ }^{62}$ Beneficiaries who changed plans after they were either auto-assigned or had their enrollment facilitated into a plan for the 2008 plan year did not have their selection changed by CMS for the 2009 plan year if their plan's premium was to go above the regional low-income subsidy. However, CMS notified these 620,000 beneficiaries that they needed to choose a new benchmark plan if they wanted to avoid paying a premium for Part D coverage in 2009.

\section{Pharmacy Access and Payment}

PDP sponsors are required to establish a pharmacy network sufficient to ensure access to covered Part D drugs for all enrollees. They must demonstrate that they provide (1) convenient access to retail pharmacies for all enrollees, (2) adequate access to home infusion pharmacies for all enrollees, (3) convenient access to long-term care (LTC) pharmacies for residents of LTC facilities, and (4) access to Indian Health Service, Tribes, or Urban Indian Programs pharmacies operating in the sponsor's service area. ${ }^{63}$

\section{Any Willing Pharmacy}

Part D sponsors are required to permit any pharmacy willing to accept the sponsor's standard contracting terms and conditions to participate in the plan's network. CMS notes that the sponsors' standard terms and conditions may vary to accommodate geographic areas and types of pharmacies; however, all similarly situated pharmacies are to be offered the same standard terms and conditions. A Part D sponsor may not require a network pharmacy to accept insurance risk as a condition of participation in its pharmacy network.

As a general rule, any pharmacy can participate in a Part D plan's network. However, plans may negotiate with a smaller number of pharmacies, or pharmacy chains, to become preferred pharmacies. In such instances, while beneficiaries have the option of going to any one of a large number of pharmacies in their community, by going to a preferred pharmacy, they would in general have lower cost sharing.

\section{Retail Pharmacy Access}

Part D sponsors must secure the participation in their pharmacy networks of a sufficient number of pharmacies that dispense drugs directly to patients (other than by mail order) to ensure

\footnotetext{
${ }^{62}$ Laura Summer et al., "Medicare Part D 2009 Data Spotlight: Low-Income Subsidy Plan Availability,” Kaiser Family Foundation, November 2008.

${ }^{63}$ CMS can waive the standards in the case of (1) MA-PD plans that operate their own pharmacies, provided they can demonstrate convenient access, and (2) private-fee-for-service plans offering Part D coverage for drugs purchased from all pharmacies, provided they do not charge additional cost sharing for drugs obtained from non-network pharmacies.
} 
convenient access to covered Part D drugs by plan enrollees. CMS defines convenient access as follows:

- In urban areas, at least $90 \%$ of Medicare beneficiaries in the Part D sponsor's service area on average live within 2 miles of a retail pharmacy participating in the sponsor's network.

- In suburban areas, at least $90 \%$ of Medicare beneficiaries in the sponsor's service area on average live within 5 miles of a retail pharmacy participating in the sponsor's network.

- In rural areas, at least $70 \%$ of Medicare beneficiaries in the sponsor's service area on average live within 15 miles of a retail pharmacy participating in the sponsor's network.

\section{Mail-Order Pharmacy Access}

The inclusion of mail order pharmacies in Part D plan networks is optional. However, such plans do not count toward meeting the retail pharmacy access requirements. Sponsors may designate a subset of formulary drugs (e.g., for particular tiers) for availability via network mail-order pharmacies. Plans that include mail-order pharmacies in their networks must allow enrollees to receive benefits, such as extended (e.g., 90-day) supply of covered drugs through a network retail pharmacy. However, beneficiaries making this choice could be subject to higher cost-sharing charges.

\section{Long-Term Care Pharmacy Access}

Part D sponsors must offer standard LTC pharmacy network contracts to all LTC pharmacies operating in their service area that request such contracts. The pharmacy must be able to meet performance and service criteria specified by CMS as well as any standard terms and conditions established by the Part D sponsor for its network LTC pharmacies. Part D sponsors may not rely on out-of-network pharmacies to meet the LTC convenient access standards.

\section{Out-of-Network Access}

In general, a beneficiary must go to one of the pharmacies within one's network. However, Part D sponsors must ensure that their enrollees have adequate access to covered Part D drugs dispensed at out-of-network pharmacies when those enrollees cannot reasonably be expected to obtain covered Part D drugs at a network pharmacy. If a plan offers a mail-order option, a beneficiary can have a prescription filled at a local pharmacy or through mail order. Enrollees will likely be required to pay more for a covered Part D drug purchased out-of-network than one purchased at a network pharmacy.

\section{Payments to Pharmacies}

Plan sponsors negotiate with pharmacies to include a sufficient number and geographic distribution of pharmacies in their networks. The plan reimburses the pharmacy for the cost of the drug, plus a dispensing fee. Pharmacies set their own rates for dispensing drugs but may give the plan a discount on their usual rate. 
MIPPA included provisions directed at prompt payments to pharmacies and related issues. ${ }^{64}$ For plan years beginning on or after January 1, 2010, the negotiated contracts between pharmacies and PDP sponsors or MA-PD plans will be required to pay all "clean claims" submitted by pharmacies within the "applicable number of calendar days" after the date on which the claim is received. ${ }^{65}$ This requirement will not apply to pharmacies that dispense drugs by mail order only or are located in, or contract with, a long-term care facility. If payment is not issued, mailed, or otherwise transmitted within the applicable number of calendar days after a clean claim is received, the PDP sponsor or MA-PD plan will be required to pay interest to the pharmacy that submitted the claim.

MIPPA also provided that for plan years beginning on or after January 1, 2010, contracts between PDP sponsors and pharmacies located in or contracting with long-term care facilities will be required to allow pharmacies between 30 and 90 days to submit claims for reimbursement. Additionally, for plan years beginning on or after January 1, 2009, contracts between pharmacies and PDP sponsors or MA-PD plans that use the cost of a drug as the standard for reimbursement of pharmacies are required to provide that the sponsor update the standard at least every seven days, to accurately reflect the market price of acquiring the drug.

\section{Employer Subsidies}

MMA included provisions designed to encourage employers to continue to offer drug benefits to their Medicare-eligible retirees. Employers have a number of options in how they can provide prescription drug coverage to Medicare-eligible retirees.

\section{Retiree Drug Subsidy}

Employers and union groups that provide prescription drug insurance to their Medicare-eligible retired workers that is at least as generous as Part D coverage may apply to receive retiree drug subsidies (RDS) from Medicare. For a plan to participate, the sponsor's drug benefits must be at least actuarially equivalent to standard prescription drug coverage under Part D. Sponsors must submit applications to CMS no later than 90 days prior to the beginning of the plan year and receive approval in order to receive the subsidy.

In 2009, qualified sponsors receive a federal tax-free subsidy equal to $28 \%$ of the allowable gross retiree prescription drug costs over $\$ 295$ through $\$ 6,000$ for each beneficiary who is enrolled in the employment-based plan instead of Part D. ${ }^{66}$ The dollar amounts are adjusted annually by the percentage increase in Medicare per capita prescription drug costs. In addition to encouraging employers to maintain drug coverage for their retirees, the RDS payments are generally less

\footnotetext{
${ }^{64}$ Interim final rule published September 18, 2008; 73 Federal Register 54226.

${ }^{65}$ The term "applicable number of calendar days" is defined as 14 days for claims submitted electronically and 30 days for claims submitted otherwise. "Clean claims" are defined as those claims that have no defect or impropriety, such as the lack of any required substantiating documentation, or any circumstances requiring special treatment that prevents timely payment from being made.

${ }^{66}$ The subsidy in 2009 is limited to $\$ 1,597.40$ per beneficiary.
} 
expensive for Medicare than enrolling these beneficiaries in a Part D drug plan. In 2008, the average RDS payment was about $\$ 560$ per beneficiary. ${ }^{67}$

Subsidy payments are made on behalf of individuals who meet the criteria for a qualifying covered retiree. These standards require that the individual be entitled to Medicare benefits under Medicare Part A or enrolled in Medicare Part B, and live in the service area of a Medicare Part D plan; however, the individual cannot be enrolled in a Medicare Part D plan. The individual must also be a retired participant in the employer's qualified group health plan or the Medicareenrolled spouse or dependent of the retired participant.

An individual retiree can elect to enroll in Part D, even if the former employer has elected to take the subsidy. (The employer would no then longer receive the subsidy payments for this individual.) However, any payments made by the employer plan would not count toward meeting the true out-of-pocket requirements.

In 2008, 6.7 million Medicare beneficiaries were enrolled in employer plans receiving the RDS; in 2009, 6.0 million receive drug coverage from these plans. As of October 2008, approximately 3,600 public and private employers have at least one approved application for the RDS. ${ }^{68}$

\section{Alternatives}

Employers or unions may select an alternative option (instead of taking the subsidy) with respect to Part D. These options include the following:

- They may elect to pay a portion of the Part D premiums for their eligible retirees.

- They may elect to set up their own separate plan that supplements, or "wraps around" Part D coverage. ${ }^{69}$

- Employers or unions may contract with a PDP or MA-PD to offer the standard Part D prescription drug benefits or enhanced benefits to its Medicare eligible retirees.

- Finally, they may become a Part D plan sponsor themselves for their retirees.

\section{Program Oversight}

The size, nature, and complexity of the Medicare Part D program put it at particular risk for fraud, waste, and abuse. For example, the Part D program involves particularly vulnerable beneficiaries, high-cost populations, and substantial control by plan sponsors, and creates a whole new category of payments and financial relationships. A variety of entities are involved in carrying out

\footnotetext{
${ }^{67} 2009$ Annual Report of the Boards of Trustees, p. 163.

${ }^{68} \mathrm{CMS}$, http://www.cms.hhs.gov/EmployerRetireeDrugSubsid/Downloads/RDS_Sponsors_PY08_10_06_08.pdf. The federal government elected not to take the employer subsidy for individuals enrolled in the Federal Employees Health Benefits program or TRICARE on the grounds that it would be merely subsidizing itself.

${ }^{69}$ This approach may have some financial consequences for the employer or union since third-party payments do not count toward TrOOP. Thus, if an employer chooses to pay some of the Part D cost sharing on behalf of its retirees, this would have the effect of delaying the point at which the Part D catastrophic coverage would begin.
} 
oversight activities to ensure compliance with program requirements and to identify potentially fraudulent activities.

\section{CMS Oversight}

CMS is responsible for preventing and detecting fraud and abuse in Medicare Part D and ensuring sponsors' compliance with applicable requirements. CMS conducts a wide variety of oversight activities, such as bid reviews, risk-adjustment validation reviews, financial and accounting reviews, program audits, and Part D LIS readiness audits. ${ }^{70}$ Some of the management controls used in the routine operation of Medicare Part D have both a primary role in the administration of the benefit and a secondary role of fraud prevention and detection.

For each plan sponsor, CMS establishes a point of contact (account manager) for all communications with the plan. The account managers work with plans to resolve any plan problems, including compliance issues. In June of 2008, CMS reorganized the Center for Drug and Health Plan Choice to enhance focus on compliance and oversight activities, including consolidating Medicare Parts $\mathrm{C}$ and $\mathrm{D}$ data collection, measurement development, and performance analysis activities to facilitate a more data-driven approach to monitoring and oversight.

As part of its oversight strategy, CMS conducts routine program audits to ensure compliance with various program requirements, including enrollment and disenrollment, marketing and beneficiary information, grievances, pharmacy access, coordination of benefits, claims processing and payment, and grievances and coverage determinations. ${ }^{71} \mathrm{CMS}$ can also conduct separate, focused audits to confirm that a previously identified deficiency has been corrected or if there is an indication of noncompliance. These audits include a combination of desk and on-site activities.

In financial audits, CMS looks at the accuracy and validity of data reported by the plans. These audits, normally conducted after the payment reconciliation, may examine things such as possible overpayments to plans, misrepresentation of bids, underreporting of rebates, and inaccurate prescription drug event data. If financial audits identify problems, CMS will recalculate payment reconciliation for that sponsor and target the sponsor for a future audit. GAO reported that because of budget constraints, CMS completed only half the number of financial audits of 2006 plan year data that it intended to complete by October $2008 .^{72}$

If egregious problems are identified, CMS actions can range from warning letters to civil monetary penalties or removal from the program, depending on the extent to which plans have violated Part D program requirements.

\footnotetext{
${ }^{70}$ However, the only statutorily required activity is that CMS conduct financial audits of one-third of the plans each year. Social Security Act $§ 1860 \mathrm{D}-12(\mathrm{~b})(3)(\mathrm{C})$.

${ }^{71}$ CMS, "Medicare Prescription Drug Plan Sponsor Part D Audit Guide,” Version 1.0, April 10, 2006. http://www.cms.hhs.gov/PrescriptionDrugCovContra/Downloads/PDPAuditGuide.pdf.

${ }^{72}$ Medicare Part D Prescription Drug Coverage: Federal Oversight of Reported Price Concessions Data, GAO-081074R, September 30, 2008.
} 


\section{Oversight Responsibilities of Part D Sponsors}

CMS requires plan sponsors to conduct activities to monitor and correct their own behavior, as well as the behavior of those they contract with. Part D sponsors are required by law to implement a comprehensive fraud and abuse program to detect, correct, and prevent fraud, waste, and abuse. Chapter 9 of CMS's Prescription Drug Benefit Manual provides both interpretive rules and guidelines for sponsors to follow in the development of this plan. ${ }^{73} \mathrm{CMS}$ is currently updating this chapter in response to recent regulatory changes and expects to issue the new version in late spring of $2009 .^{74}$

Among other requirements, Part D sponsors are required to have and implement an effective compliance plan as a condition of participation in the Medicare program. Elements of an effective plan include written policies and procedures; a designated compliance officer and committee; training and education, effective lines of communication, well-publicized disciplinary guidelines, and internal monitoring and auditing; and prompt response to detected offences and development of corrective actions.

Beginning January 1, 2009, Part D sponsors are to provide fraud, waste, and abuse training and education to their first tier, downstream, and related entities. ${ }^{75}$ This includes pharmacists, pharmacy clerks, and others who are employed by entities that plans contract with to provide the Medicare drug benefit.

\section{Medicare Prescription Drug Integrity Contractors}

CMS contracts with private firms, Medicare Prescription Drug Integrity Contractors (MEDICs), to perform a variety of fraud prevention detection activities. MEDIC responsibilities include conducting complaint investigations; performing data analysis; developing and referring cases to law enforcement, as well as supporting ongoing investigations; conducting audits; and beginning in September 2008, reviewing PDP and MA-PD fraud and abuse compliance programs. For example, a benefit integrity audit, also called a targeted audit, is performed if there is a concern that the activities of a sponsor could put the program and/or a beneficiary at risk.

MEDICs are also responsible for working with other entities to coordinate fraud prevention and detection efforts, including the Part D sponsors, other Medicare contractors, the HHS Office of Inspector General (OIG), the Department of Justice, and state agencies.

There are currently two MEDIC regions. The MEDIC North contractor is Electronic Data Systems Corporation, and the MEDIC South Contractor is Delmarva/Health Integrity.

\footnotetext{
${ }^{73}$ CMS, "Prescription Drug Benefit Manual,", chapter 9, Rev. 2, April 25, 2006, http://www.cms.hhs.gov/ PrescriptionDrugCovContra/Downloads/PDBManual_Chapter9_FWA.pdf .

7472 Federal Register 68700, "Revisions to the Medicare Advantage and Part D Prescription Drug Contract Determinations, Appeals and Intermediate Sanctions Processes," published December 5, 2007.

${ }^{75}$ Ibid.
} 


\section{Issues}

The Medicare prescription drug program is now in its fourth year of operation. While early startup issues have generally been resolved, some issues remain and other issues are emerging. Additionally, initial reviews of the operations of the program have been completed and shed some light on areas where efficiencies may be realized, as well as areas where program vulnerabilities exist. Finally, discussions regarding the overall structure of the program benefits, costs to beneficiaries, and the pricing of and access to prescription drugs continue.

\section{Beneficiary Costs}

The basic structure of the Part D benefit, including the coverage gap and the ability of private health plans to affect access through deductibles, cost sharing, and drug formularies, may contribute to problems with affording prescription drugs, particularly for lower-income beneficiaries who do not qualify for the low-income subsidy. These features mean that out-ofpocket costs can vary considerably over the course of a year and depend on the specific drugs beneficiaries' physicians prescribe for them. It is possible that drug access problems for Medicare beneficiaries may grow in the future.

\section{Premium Costs}

More than $90 \%$ of beneficiaries would have experienced an increase in premiums between 2008 and 2009 if they did not change drug plans. ${ }^{76}$ In their 2009 March report to Congress, MedPAC noted that if enrollees stayed in the same PDP, their premiums have risen by an average of $\$ 6$ above the average 2008 level of $\$ 25$ to nearly $\$ 31$ per month, a $24 \%$ increase.

CMS attributed the hikes to rising drug costs, a change in how premium benchmarks are weighted for 2009, and plans' higher-than-expected costs for providing drug coverage above the catastrophic limit. In recent testimony, MedPAC Chairman Glenn Hackbarth suggested that the increases may have to do with pricing strategies to maximize market share, inadequate riskadjustment, and monopolistic behavior by manufacturers of high-cost, single-source drugs. ${ }^{77}$

\section{Coverage Gap}

The number of PDPs offering drug coverage in the coverage gap continues to decline. An estimated 8.3 million Part D enrollees reached the coverage gap in $2007 .{ }^{78}$ Approximately 2.9 million of those were not eligible for LIS or enrolled in a plan with gap coverage, and were therefore responsible for the full cost of their prescriptions. In 2009, only about $25 \%$ of PDPs and $51 \%$ of MA-PD plans offer some sort of gap coverage. ${ }^{79}$

\footnotetext{
${ }^{76}$ Kaiser Family Foundation, Medicare Part D 2009 Plan Spotlight: Premiums (November 2008); http://www.kff.org/ medicare/upload/7835.pdf.

${ }^{77}$ Response to Member question, before House Committee on Ways and Means, Subcommittee on Health, March 17, 2009.

${ }^{78}$ CMS, October 30, 2008, Medicare Prescription Drug Benefit Symposium, "Beneficiary Experience," http://www.cms.hhs.gov/PrescriptionDrugCovGenIn/08_PartDData.asp.

${ }^{79}$ Jack Hoadley et al., "Medicare Part D 2009 Data Spotlight: The Coverage Gap," Kaiser Family Foundation, (continued...)
} 
Recent studies have found that some enrollees do not take needed medications when reaching the coverage gap. One study that looked at utilization of drugs in eight drug classes found that, on average, $15 \%$ of beneficiaries using drugs in these classes stopped taking them once they reached the gap. ${ }^{80}$ According to findings from the Center for Studying Health System Change's 2007 Health Tracking Household Survey, ${ }^{81}$ about 2.5 million Medicare beneficiaries went without at least one prescribed medication because of finances. Twenty-one percent of dual-eligible beneficiaries were also in this category, despite receipt of the low-income subsidy.

With many Part D enrollees at risk of forgoing needed medications in the coverage gap, or of incurring high out-of-pocket spending, concerns related to the coverage gap are likely to continue. Suggestions to address these problems have included proposals to simplify the benefit design by requiring that plans cover all generics, all brands, or no drugs in the coverage gap and clearly describe these definitions in the benefit descriptions. CBO has also proposed extending the benefit's initial $25 \%$ coinsurance rate up to the point at which the catastrophic threshold is reached. Implementing this option would increase total mandatory spending by an estimated $\$ 134$ billion from 2010 through 2019. ${ }^{82}$

\section{Utilization Controls}

The trend annually among plans has been to impose higher cost sharing and utilization management controls to address the high cost of some drugs. For example, placing high-cost drugs in specialty tiers where cost sharing is set at a percentage of the cost of the drug can make these drugs unaffordable for some beneficiaries. There is concern that these kinds of structures pass additional costs to beneficiaries with the greatest health care needs. Additionally, although Medicare beneficiaries pay substantially more for specialty-tier drugs than for drugs on other tiers, Part D regulations preclude them from requesting an exception to reduce cost sharing for specialty drugs.

To illustrate, research conducted by Avalere Health and the American Cancer Society Cancer Action Network found that Medicare stand-alone PDPs have been increasingly shifting namebrand oral cancer drugs to higher formulary tiers over the past four years, meaning that each year consumers face higher cost sharing for these products. ${ }^{83}$ In 2009, the large majority of PDPs placed name-brand oral oncology products on specialty tiers that require cost sharing of $26 \%$ to $35 \%$ for each prescription. Additionally, PDPs are increasing their use of prior authorization to control access to branded cancer drugs. The American Cancer Society is concerned that the shifts in drug coverage may limit access to treatment for people with cancer and reduce their treatment options.

\footnotetext{
(...continued)

November 2008.

${ }^{80}$ Ibid.

${ }^{81}$ James D. Reschovsky and Laurie E. Felland, Center For Studying Health System Change, "Access to Prescription Drugs for Medicare Beneficiaries," Results from the Community Tracking Study, No. 23, March 2009.

${ }^{82}$ Congressional Budget Office, Budget Options, Volume 1: Health Care, December 2008, p. 164.

${ }^{83}$ Lisa Murphy et al., Avalere Health, Christy Schmidt, and Sarah Barber, American Cancer Society Cancer Action, "Network Cost Sharing for Cancer Patients in Medicare, 2009," December 2008.
} 
One suggestion to help stem rising consumer costs associated with expensive specialty tier prescription drugs is to create a regulatory pathway for generic versions of biologic drugs and drive down costs through competition. Other suggestions are to limit the cost sharing for specialty tiers to $25 \%$ and to allow an exceptions process for specialty tiers.

There is also concern that plans have been given too much discretion in setting negotiated prices and thus may allow the inclusion of a wider range of therapies in the specialty tier (i.e., exceed the $\$ 600$ threshold). Suggestions have included requiring plans to better define the way in which they calculate the threshold amount.

\section{Program Costs}

While Part D has increased medication access for Medicare beneficiaries, questions about cost continue to arise, and strategies to reduce and/or contain these costs are at the forefront of discussions related to Part D.

\section{Part D Means-Testing}

Most Part D enrollees pay a standard premium that is intended to cover about $25 \%$ of the program's average costs per capita. By comparison, Medicare's Part B charges progressively higher premiums for beneficiaries whose income exceeds certain levels. Means-testing Medicare Part D has been included in the President's 2010 budget as a cost-containment strategy, with estimated savings of $\$ 8.1$ billion by 2019 . The income levels and monthly adjusted premiums used to determine higher premiums for Part D would be the same as that applied to means-testing Part B. For 2009, that would mean that beneficiaries making at least $\$ 85,000$ for an individual income tax return and $\$ 170,000$ for a joint return would be charged additional premiums. ${ }^{84}$ Proponents of this option maintain that it would offer budgetary savings but leave the majority of Part D enrollees unaffected. CBO estimates that fewer than $6 \%$ of Part D enrollees would face a higher premium in a given year, and all of those individuals would still be receiving subsidized coverage. ${ }^{85}$

Beneficiary advocacy groups maintain that the cost savings estimates are too high and are concerned about any additional economic pressures on retirees, especially in a difficult economy. Additionally it is possible that some higher income enrollees might react by opting out of the Part D program. ${ }^{86}$

\footnotetext{
${ }^{84}$ The higher monthly Part B premium amounts for 2009 are based on 2007 income levels and are (1) \$134.90-for single beneficiaries with income $\$ 85,001-\$ 107,000$ or for each member of a couple filing jointly with income $\$ 170,001-\$ 214,000 ;$; (2) \$192.70 — for single beneficiaries with income $\$ 107,001-\$ 160,000$ or for each member of a couple filing jointly with income $\$ 214,001-\$ 320,000$; (3) $\$ 250.50$ - for single beneficiaries with incomes $\$ 160$, 001$\$ 213,000$ and each member of a couple filing jointly with income $\$ 320,000-\$ 426,000$; and (4) \$308.30_for single beneficiaries with incomes greater than $\$ 213,000$ and each member of a couple filing jointly income above $\$ 426,000$.

${ }^{85}$ Congressional Budget Office, Budget Options, Volume 1: Health Care, December 2008, p. 164.

${ }^{86} \mathrm{CBO}$ estimates that about $1 \%$ of Part D enrollees would ultimately decline to enroll in the program or delay enrollment as a result of these higher premiums.
} 


\section{Negotiation of Drug Prices}

One of the most prominent issues relates to whether negotiation of drug prices should remain in the private sector or whether the federal government should be involved. Proponents of government involvement in negotiation of drug prices believe that the government could leverage its purchasing power to obtain lower drug prices. Some Members of Congress, contending that the combined purchasing power on behalf of all Medicare Part D beneficiaries could be used as leverage, have proposed amending the law to provide for the Secretary of HHS to negotiate directly with drug manufacturers. Opponents believe that market competition among private plans would result in lower overall drug prices, and that direct government negotiation could lead to a restriction of formulary choice and reduced funding for research and development. There is also some concern that pricing of medications for non-Medicare beneficiaries would be raised to offset the lower prices to Medicare.

CBO has concluded that while cost savings may be possible in selective instances, the impact of government negotiations would likely be limited. ${ }^{87}$ Additionally, drug manufacturers could seek to limit the impact of the Secretary's actions by setting higher initial prices for their drugs to offset any potential price concessions from negotiations with the Secretary. The key factor in determining whether negotiations would lead to price reductions is the leverage that the Secretary would have to secure larger price concessions from drug manufacturers than competing PDPs currently obtain. When several drugs are available to treat the same medical condition, PDPs can secure rebates from selected drug manufacturers by giving their drugs preferred status within formularies. CBO stated that negotiation is likely to be effective only if it is accompanied by some source of pressure on drug manufacturers to secure price concessions.

\section{Public Option}

The rise in Part D premiums, the drop in the number of low cost options, and potentially discriminatory cost-sharing structures have led some to conclude that private markets without competition from a public health insurance plan option are not able to control costs and provide stability for beneficiaries.

With the creation of a publically administered prescription drug plan, seniors could chose between a government-operated plan that could negotiate directly with drug companies to lower medication prices. Proponents of such legislation maintain that this would create fair-market competition and lead to less costly drug choices for Medicare recipients. Opponents of this option believe that the competitive market approach is working well for beneficiaries and taxpayers and do not see a reason for the government to inject itself into the process.

\section{Price Transparency}

The Part D program relies on sponsors to generate prescription drug savings, in part, through their ability to negotiate price concessions such as rebates and discounts, with drug manufacturers and retail pharmacies. Sponsors must report the price concession amounts to CMS and pass some of

\footnotetext{
${ }^{87}$ Congressional Budget Office, Letter to the Honorable Ron Wyden regarding Medicare's ability to negotiate prices for drugs covered by Part D, April 10, 2007.
} 
these price concessions on to the beneficiaries. CMS uses the reported data to calculate final payments; however, much of the information submitted to CMS is protected from disclosure.

GAO has reported challenges in the oversight of federal prescription drug programs that rely on privately reported data. ${ }^{88} \mathrm{CMS}$ officials noted that variation in defining and reporting price concessions data, such as variation in how sponsors allocate manufacturer rebates between their Part D plans and other businesses, are likely to create oversight challenges. GAO identified CMS's actions to ensure that the price information Part D sponsors report to CMS include the aggregate price concessions that sponsors negotiate with PBMs and drug manufacturers as an area for congressional oversight.

A key question is where rebates to PDPs lie in the overall distribution of rebates and, consequently, how the net cost of drugs acquired by PDPs compares to the net cost other purchasers face. $\mathrm{CBO}$ has suggested that PDPs have secured rebates somewhat larger than the average rebates observed in commercial health plans. ${ }^{89}$ An October 2007 report conducted by the Committee on Oversight and Government Reform concluded that Part D plans received low average rebates compared to Medicaid or the VA.

The lack of transparency in the actual net prices plan sponsors pay for drugs may result in overpayments to plans by Medicare. One option suggested by CBO is to require manufacturers of brand-name drugs to pay the federal government a rebate equaling $15 \%$ of the average manufacturer price. ${ }^{90}$ Under this option, manufacturers would be required to participate in the rebate program in order for their drugs to be covered by parts B and D of Medicare, by Medicaid, and by the VA.

\section{Classes of Clinical Concern}

CMS has required Part D to cover all, or substantially all, of the drugs in six drug categories to ensure that beneficiaries have continued access to certain therapies for which restricted access could have serious clinical consequences. Additionally, MIPPA required the Secretary to identify categories and classes of drugs for which restricted assess to these drugs would have major or life-threatening consequences, and there is a significant need for individuals to have access to multiple drugs in this category.

There are concerns that if sponsors are required to offer all drugs in a category, there is little to no leverage for sponsors in negotiating with manufacturers and wholesalers to provide discounts. Therefore it may be difficult for sponsors to offer drugs at reduced prices (e.g., preferred drugs), thus resulting in potentially higher costs to Medicare and its beneficiaries. It is also possible that CMS's review could lead to additional drugs being added to those in the six classes already identified, thus resulting in potential additional increased costs to Medicare and its beneficiaries. A survey conducted by Milliman estimates that the inclusion of all drugs in certain designated classes could cost the Medicare program as much as an additional \$511 million per year. ${ }^{91}$

\footnotetext{
${ }^{88}$ Government Accountability Office, "Medicare Part D Prescription Drug Coverage: Federal Oversight of Reported Price Concessions Data" (GAO-08-1074R), September 30, 2008.

${ }^{89}$ Congressional Budget Office, Letter to the Honorable Joe Barton and the Honorable Jim McCrery on the public disclosure of price rebates, March 12, 2007.

${ }^{90}$ Congressional Budget Office, Options for Health Reform, December 2008.

${ }^{91}$ Milliman, Medicare Part D Administrator Survey: Potential Cost Impacts Resulting from CMS Guidance on "Special (continued...)
} 


\section{Marketing}

In spite of recent changes in the law that place greater restrictions on marketing activities, marketing problems continue. For example, some beneficiaries have been pressured into buying Medicare insurance plans that they do not understand or want. In some cases, beneficiaries are sold Medicare Advantage plans without realizing that this means leaving traditional Medicare. ${ }^{92}$ CMS's call letter for the 2010 plan year, issued March 30, 2009, also notes that in spite of actions over the last few years to strengthen marketing requirements and oversight, particularly of agent and broker conduct, "some of our contractors and related third-party entities attempt to find ways to circumvent our rules and guidelines." "exorbitant" fees to agents for making a referral and noted that in some instances referral fees exceeded the total compensation that can be paid to agents under Medicare rules.

As an example, in a February 19, 2009 letter, CMS notified the Tampa-based provider WellCare Health Plans Inc. that as of March 7, 2009, the company's Medicare enrollment and marketing activities would be suspended. Among the compliance problems cited was that WellCare engaged in activities that "misled and confused Medicare beneficiaries and misrepresented its organization." The company also engaged in unauthorized door-to-door solicitation and failed to establish and maintain a system for confirming that enrolled beneficiaries had, in fact, enrolled in its plan and understood the rules applicable to the plan. WellCare also failed to identify, monitor, and correct practices of agents who misrepresented its plans, including failing to discover forged applications through its own monitoring systems.

Part D related marketing activities will require continued monitoring and oversight to determine whether new laws and CMS requirements would result in fewer marketing abuses. However, in cases where the applicable requirements are not being adhered to, attention may need to be given to developing additional strategies to deter and/or stop inappropriate marketing activities.

\section{Plan Selection and Enrollment}

The structure of the Part D program, and the large number of plans in each region, can make a comparison of plans difficult. For example, beneficiaries must consider premiums, cost sharing, and costs covered in the coverage gap. They also must check whether the drugs they use will be covered by their plan and under what conditions. In spite of the many resources available to beneficiaries to assist them in selecting a plan, many observers have suggested that the range of plan options is confusing for some Medicare beneficiaries and that, as a result, beneficiaries may not enroll in the plans that best meet their needs.

Recent studies have also concluded that most beneficiaries do not have access to understandable information or effective assistance for making good decisions about their health care options. For example, a GAO study noted that the Annual Notice of Change (ANOC) contains language at too high a level for some beneficiaries and contained much needless and overly technical

(...continued)

Protections for Six Protected Drug Classifications" and Section 176 of the Medicare Improvements for Patients and Providers Act of 2008 (MIPPA) (P.L. 110-275), October 16, 2008, http://www.amcp.org/amcp.ark?p=AA8CD7EC.

${ }^{92}$ See CRS Report R40374, Medicare Advantage, by Paulette C. Morgan, for issues specific to MA.

${ }^{93} \mathrm{http} / / /$ www.cms.hhs.gov/PrescriptionDrugCovContra/Downloads/2010CallLetter.pdf. 
information. ${ }^{94} \mathrm{GAO}$ also noted that CMS did not take steps to formally evaluate this notice for the 2008 and 2009 enrollment periods for effectiveness in communicating plan changes. ${ }^{95}$

Additionally, a recent report found that in 2006, most of the seniors in the analysis did not choose the lowest-cost Part D plan available to them.${ }^{96}$ It is possible that beneficiaries chose a plan that contracts with a convenient pharmacy that may not be the lowest cost plan, that beneficiaries make their selections based on the nature of utilization restrictions, that they select a plan with a strong brand name, or are simply confused by the number and complexity of the plan offerings.

To make drug plan offerings more understandable and easier to compare, some have advocated for imposing standardization among plans to reduce variation (e.g., similar to Medigap plans) and/or limiting the number of Part D plans offered in each region. Additionally some, such as GAO, have suggested that CMS expand oversight to ensure that information provided to beneficiaries about their plan choices is accurate and understandable.

\section{Appeals Process}

There are concerns that the number of layers of the appeals and associated time delays can mean that beneficiaries may go without medically necessary drugs for an extended period. Additionally, the process can be confusing and information about the process may not always be readily available to beneficiaries when needed. Suggestions to help ensure timely access to nonformulary drugs or non-preferred drugs include requiring that information on the appeals process is provided at the pharmacy, and establishing a more efficient appeals process with fewer administrative burdens.

\section{Low-Income Beneficiaries}

The Medicare drug benefit offers substantial help to low-income Medicare beneficiaries, who generally have more medical and pharmaceutical needs than higher-income beneficiaries. Issues of concern with regard to the LIS program include lower than anticipated enrollment in LIS and the declining availability of LIS plans.

A continued interest will be the ability to identify and enroll persons eligible for the low-income subsidy who are not currently enrolled. Approximately one in five low-income Medicare beneficiaries estimated to be eligible for this assistance are not receiving it, and many individuals with low incomes do not qualify because their resources are just above the allowable threshold. In a September 2008 study, ${ }^{97}$ GAO found that in 2006 and 2007, applicants denied the LIS often exceeded the asset threshold by a relatively small amount, and in both years more than onequarter of these applicants exceeded the threshold by less than $\$ 5,000$.

\footnotetext{
94 "Medicare Part D: Opportunities Exist for Improving Information Sent to Enrollees and Scheduling the Annual Election Period," GAO-09-4, December 12, 2008.

${ }^{95}$ In the 2010 call report, CMS indicated that they have initiated an evaluation of all of their annual beneficiary materials for the 2010 AEP and that the agency will look at reading levels, effectiveness and length.

${ }^{96}$ Gruber, Jonathan, "Choosing a Medicare Part D Plan: Are Medicare Beneficiaries Choosing Low-Cost Plans?" commissioned by the Kaiser Family Foundation, March 2009.

${ }^{97}$ Medicare Part D Low-Income Subsidy: Assets and Income Are Both Important in Subsidy Denials, and Access to State and Manufacturer Drug Programs Is Uneven, GAO-08-824, September 5, 2008.
} 
Additionally, the number of Medicare drug plans available to LIS recipients for no monthly premium has steadily declined since 2007. In 2009, LIS beneficiaries in most states have only a handful of PDPs available to them for no monthly premium, compared with the non-LIS beneficiaries who may have close to 50 plans to choose from. Although LIS beneficiaries have the right to switch plans at any time, those who choose to shop around are faced with increasingly limited options if they want to maintain their full premium subsidy.

The decline in the availability of LIS plans has led to the disruption in drug coverage for lowincome Part D enrollees, affecting more than 1.0 million low-income beneficiaries between 2006 and 2007, 2.1 million between 2007 and 2008, and 1.6 million between 2008 and 2009. This does not include the LIS beneficiaries (over 600,000 in 2008) who switched out of the plan to which they were originally assigned and who needed to enroll in another plan to avoid paying premiums and cost sharing. Additionally, the random process for assigning low-income recipients to Part D plans has raised concerns because it does not take into account the specific drug needs of the individual and can possibly lead to negative consequences for enrollees' access to medications.

A number of potential solutions to address these problems have been promoted. One option would be for CMS to increase the pool of plans available to LIS recipients to include plans that offer enhanced benefits if their premiums are below the regional benchmarks. Additionally, Congress could review how the Part D low-income subsidy benchmark is calculated and whether a statutory change is needed to ensure that enough plans qualify each year to offer zero-premium coverage to low-income enrollees. An approach to ensure that LIS beneficiaries are enrolled in the best plans for them would be to adopt a more beneficiary-centered way to assign beneficiaries to plans based on their individual drug needs. Suggestions to address enrollment issues have also included permitting seniors to keep more of their assets and still qualify for the Medicare lowincome assistance.

\section{Adequacy of Oversight}

Reports by OIG and GAO raise questions about the oversight of the Part D program by CMS and plan sponsors' compliance with fraud and abuse detection policies. Shortcomings identified include failures to conduct effective training and education for staff or implement procedures for effective internal monitoring and auditing. Additionally, there are concerns that Part D plans' fraud and abuse programs are designed largely to protect the plans themselves rather than the Medicare program or its beneficiaries

For example, a 2008 GAO report noted that "little is known about the extent to which Part D sponsors have implemented their fraud and abuse programs or the extent of CMS's oversight of Part D sponsors' programs." 98 CMS's oversight of the plans was primarily limited to the review and approval of sponsors' fraud and abuse program plans submitted as part of the plans' initial application for the program. The report also noted that CMS had not conducted its own audit of Part D plan fraud and abuse programs in 2007 and did not plan to conduct any in 2008. In response to the GAO report, CMS noted that it had relied on self-assessment by the sponsors because of a lack of adequate funding for adequate on-site fraud and abuse program audits.

\footnotetext{
98 "Medicare Part D: Some Plan Sponsors Have Not Completely Implemented Fraud and Abuse Programs, and CMS Oversight Has Been Limited" (July 2008), GAO-08-760.
} 
Future discussions may focus on issues such as the adequacy of funding for Part D oversight (and funding for Medicare program oversight activities in general), the efficiency and effectiveness of current fraud and abuse detection activities, and identification and development of improved oversight methods and tools.

\section{Author Contact Information}

Patricia A. Davis

Specialist in Health Care Financing

pdavis@crs.loc.gov, 7-7362

\section{Acknowledgments}

Jennifer O'Sullivan made a significant contribution to this report. 